\title{
Recognition of affective prosody in brain- damaged patients and healthy controls: A neurophysiological study using EEG and whole-head MEG
}

\author{
BORIS KOTCHOUBEY \\ University of Tübingen, Tübingen, Germany \\ JOCHEN KAISER \\ University of Frankfurt/Main, Frankfurt/Main, Germany \\ VLADIMIR Bostanov AND WERNER LUTZENBERGER \\ University of Tübingen, Tübingen, Germany \\ AND \\ Niels Birbaumer \\ University of Tübingen, Tübingen, Germany \\ and National Institutes of Health, Washington, D.C.
}

\begin{abstract}
A passive oddball experiment was used in which stimuli were emotional exclamations differing in their affective tone. In both electroencephalography (EEG) and magnetoencephalography (MEG), deviants elicited an N300 component, sometimes accompanied by a slow wave. Both components had a symmetrical distribution, but the former was more posterior than the latter. The same responses to prosodic stimuli were significant in 6 of 27 patients with severe disorders of consciousness (persistent vegetative state and minimally conscious state) and in all 3 of the examined locked-in patients, indicating that the procedure can be applied for testing neurological patients. The occurrence of significant responses depended on the presence or absence of a lesion to the right temporal lobe. Obviously, the N300 depends on the activity of the right temporal cortex but does not originate there. We suggest that the component is related not to the recognition of affective prosody as such, but to the following detection of affective mismatch due to violations of emotional context of stimulation.
\end{abstract}

Whereas brain mechanisms and electrophysiological correlates of semantic processing have been studied extensively during the past decades, less attention has been paid to the electrophysiology of speech prosody. This term denotes those aspects related to intonation (melody) of spoken language and subsumes two functionally different components: linguistic prosody, which helps the perceiver to perform segmentation of the stream of spoken sentences and plays a role equivalent to punctuation in a written text; and emotional prosody, which expresses the emotions of the speaker (Scherer, 1986). The former is perceived on a rather large time scale, including whole words or phrases, on the basis of periodical changes in voice pitch, timbre, and loudness. The latter, in contrast, is perceived on a shorter time scale (e.g., phonemes) on the basis of an acoustical parameter called voice quality (Laver, 1980).

It is well known (see Kutas \& Hillyard, 1980, for written language; Connolly, Stewart, \& Phillips, 1990, for spoken language) that words not strongly semantically primed typically elicit a central or parietocentral eventrelated brain potential (ERP) component, N400. In contrast, syntactic violations or syntactically difficult constructions frequently yield other ERP components, such as the left anterior negativity (LAN) or a parietal positivity P600 (Friederici, Hahne, \& Mecklinger, 1996; Friederici, Pfeifer, \& Hahne, 1993). There is a controversy about the specificity of these effects; the P600, for example, can be found after all kinds of violations of language rules (Kotchoubey \& Lang, 2003; Münte, Heinze, Matzke, \& Wieringa, \& Johannes, 1998). Similar positive components also appear after key words in sentences, which dissolve uncertainty produced by an equivocal context (Friederici et al., 1996; Mecklinger, Schriefers, Steinhauer, \& Friederici, 1995; Osterhout, Holcomb, \& Swinney, 1994). One may, therefore, wonder whether such a late positivity would also occur when a resolution of uncertainty was 
attained not by a particular syntactical structure, but because of prosodic accents (e.g., "the workers considered the last offer from the management of the factory" vs. "the workers considered the last offer from the management was a real insult" [Marslen-Wilson, Tyler, Warren, Grenier, \& Lee, 1992]). Several studies have indicated that this is, indeed, the case (Kerkhofs, Vonk, Schriefers, \& Chwilla, 2007; Mietz, Toepel, Ischebeck, \& Alter, 2008; Steinhauer, 2003; Steinhauer, Alter, \& Friederici, 1999; Steinhauer \& Friederici, 2001). A slow positivity whose latency depended on the localization of the prosodic shift in a sentence was also obtained in senseless "sentences" consisting of pseudowords, and even in hummed sentencelike sequences (Pannekamp, Toepel, Alter, Hahne, \& Friederici, 2005). On the other hand, considerable semantic or pragmatic uncertainty caused by prosodic manipulations can elicit N400-like effects (e.g., Eckstein \& Friederici, 2005; Magne et al., 2005; Mietz et al., 2008, for electroencephalography [EEG] studies; Hayashi, Imaizumi, Mori, Niimi, \& Ueno, 2001; Imaizumi, Mori, Kiritani, Hosoi, \& Tonoike, 1998, for magnetoencephalography [MEG] studies). Also, the N400 to semantic mismatch can be modified by preceding prosodic information (Isel, Alter, \& Friederici, 2005). Whereas prosodic incongruence in the middle of the sentence tends to elicit a central or centroparietal negativity, similar manipulations with final words lead to a late positivity and a right anterior negativity (Eckstein \& Friederici, 2005; Magne et al., 2005).

Much less is known about electrophysiological effects of emotional prosody. Schirmer, Kotz, and Friederici (2002) described an emotional prosodic priming effect on word targets that was similar to the corresponding semantic priming effect (in both cases, the ERP component N400 is less in primed than in nonprimed words) but whose time course revealed gender differences unusual for semantic priming (i.e., women exhibited faster emotional priming than did men). However, when subjects had to pay attention to prosody and judge its congruence, the difference between men and women disappeared (Schirmer, Kotz, \& Friederici, 2005). Wambacq, Shea-Miller, and Abubakr (2004) reported an increased ERP positivity to spoken words with negative affective prosody (as compared with words with neutral prosody), whose latency varied as a function of attention; no interaction between the consecutive words (i.e., priming) was reported. Recently, Kotz and Paulmann (2007) and Paulmann and Kotz (2008b) used a set of sentences containing violations of emotional and semantic context. They found a late right-lateralized positivity in response to purely emotional violations and a broadly distributed negativity around $300 \mathrm{msec}$ to combined emotional and semantic violations.

All these studies employed emotionally colored spoken words that always possess some referential context regardless of their prosodic tone. This context is an additional factor, because the emotional content of a word can interact with emotional prosody in an a priori unpredictable way. To avoid this additional effect, Bostanov and Kotchoubey (2004) used emotional exclamations instead of words. Such exclamations are phylogenetically primary and still are the most powerful means for communication of purely affective contents (Goffman, 1978; Scherer \& Kappas, 1988). Most humans can recognize them almost without errors and within a very short time on the basis of the voice quality (Scherer, 1986).

Using an oddball paradigm without explicit instruction with four different emotionally positive (happy) exclamations and one emotionally negative (sad) one, Bostanov and Kotchoubey (2004) obtained an ERP negativity with a central maximum peaking about $300 \mathrm{msec}$ poststimulus as a response to violations of the actual affective context. An acoustical analysis of the exclamations and a control priming experiment revealed that this ERP component was unrelated to simple physical stimulus features such as fundamental frequency (F0) and intensity. Likewise, it cannot be attributed solely to the contrast between positive and negative affects, because a similar effect was also observed in response to a negative emotion (e.g., disgust) presented on the background of another negative emotion (e.g., fear). This component, called N300, might, therefore, be putatively regarded as an electrophysiological marker for recognition of changes in emotional prosody (Figure 1).

The significance of such a marker is determined by the fact that perception of prosody is a separate (modular) brain function largely unrelated to other aspects of spoken language processing. Double dissociations between deficient prosody recognition and other, superficially similar functional disturbances revealed an independent type of neuropsychological dysfunction, the sensory aprosodia (Adolphs, Damasio, \& Tranel, 2002; Anderson \& Phelps, 1998; Perry et al., 2001). Such patients, typically with a lesion in the right temporal lobe (RTL; Adolphs et al., 2002; Ross, Orbelo, Burgard, \& Hansel, 1998), cannot recognize the intonation of speech, although they can comprehend semantic and syntactical aspects of language. Interestingly, the aprosodia test battery developed for the assessment of this disorder comprises both linguistic and emotional aspects of prosody (Ross, 1981), and no strong evidence exists that the two can be affected independently of each other (Seddoh, 2002).

If the recognition of prosody can be disturbed while everything else works correctly, the opposite condition is also possible; that is, the recognition of prosody (possibly, of affective prosody, which is simpler than linguistic prosody) may remain the only (or one of only a few) intact cortical function(s) in a patient with otherwise severely disturbed mental capacities. Being completely unable to understand the semantic content of spoken words and sentences, such a patient might be diagnosed as being in a persistent vegetative state (PVS; Jennett, 2002; Kotchoubey, in press; Royal Colleges of Physicians, 2003). An electrophysiological test procedure, such as the passive emotional oddball described above, might reveal that some of these patients are nevertheless able to adequately perceive some nonverbal aspects of speech.

Bostanov and Kotchoubey (2004) hypothesized that their N300 elicited by prosodic mismatch may be equivalent to the N400 to semantic mismatch, but this interpretation is based mostly on the functional justification, rather than the specific spatiotemporal characteristics of the 


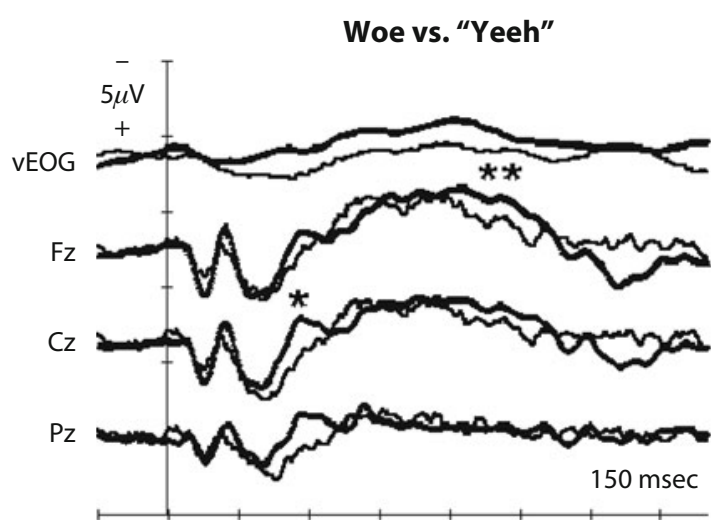

Woe vs. “Oooh”

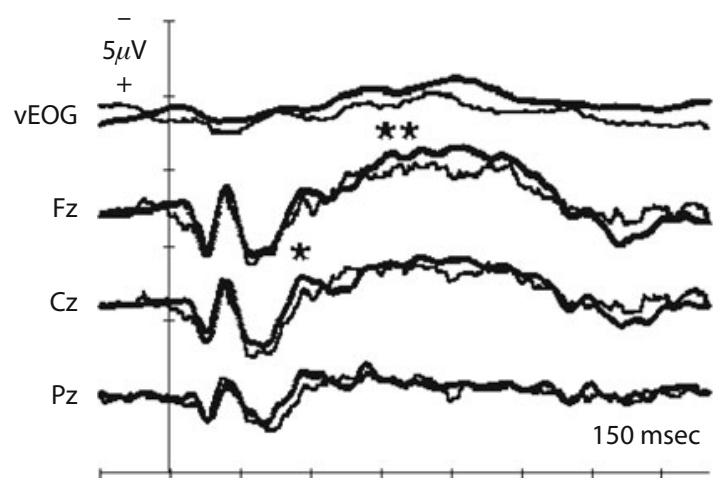

Woe vs. "Heey"

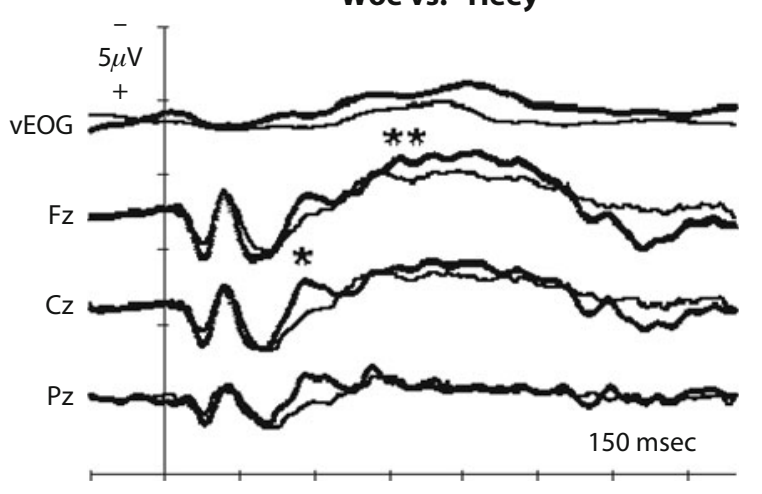

Woe vs. "Wowh"

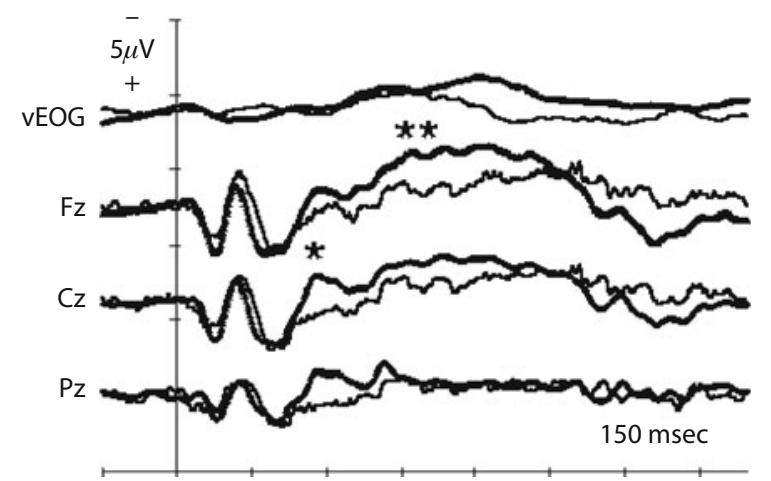

Figure 1. Event-related brain potentials to the woe exclamation (bold line) compared with the four joyful exclamations "heey," "oooh," "yeeh," and "wowh" (thin line), at midline electrode sites, based on the data of Bostanov and Kotchoubey (2004). Negativity is up. Each tick on the $x$-axis stands for $150 \mathrm{msec}$, each tick on the $y$ axis, for $5 \mu \mathrm{V}$. Note that in contrast to the figures in Bostanov and Kotchoubey, the waveforms presented here contain an equal number of standards and deviants (i.e., 60 per subject). The $\mathrm{N300}$ (marked *) is accompanied by a slow negative wave (marked ${ }^{* *}$ ). The slow wave appears to have a more anterior distribution than the $\mathrm{N300}$ and is completely absent over the parietal cortex. However, the condition $\times$ topography interaction was not significant.

component. Given a low spatial resolution in that study, alternative accounts could not be ruled out. The N300 might, for instance, belong to the family of mismatch negativities (MMNs) elicited by any acoustical deviation (Näätänen, 1992). The contemporary literature clearly indicates that MMN is produced not only by deviations in simple physical features but also by changes in very complex acoustical patterns (e.g., List, Justus, Robertson, \& Bentin, 2007; Näätänen \& Winkler, 1999; Pulvermüller, Shtyrov, Hasting, \& Carlyon, 2008; Schröger, 1997).

The aims of the present study were (1) to further explore the brain activity involved in the analysis of emotional prosodic stimulus features, and (2) to use this experimental procedure for the assessment of prosodic comprehension in neurological patients to whom the standard neuropsychological techniques cannot be applied, because of either a disorder of consciousness or severe motor paralysis. Concerning (1), we hoped that the whole-head MEG technique, with its high spatial resolution, would shed more light on the origin of the N300. As regards (2), the EEG recordings were carried out in a group of patients with extremely severe disorders of consciousness, as well as in 3 severely paralyzed patients,
2 of whom were in a complete locked-in state. During the last few years, several research groups have developed batteries of ERP tests designed for assessment of cognitive information processing, including complex memory and semantic processing, in patients with severe paralysis, disorders of consciousness, or severe aphasia (e.g., Becker \& Reinvang, 2007; Connolly \& D'Arcy, 2000; Connolly, Mate-Kole, \& Joyce, 1999; D’Arcy et al., 2003; Kotchoubey et al., 2005; Neumann \& Kotchoubey, 2004; Reinvang, 1999). However, to the best of our knowledge, these methods have never been applied for assessment of prosodic functions in the severely disabled. Evidence from both ERP (e.g., Kotchoubey et al., 2005; Wijnen, van Boxtel, Eilander, \& de Gelder, 2007) and imaging (e.g., Laureys, Giacino, Schiff, Schabus, \& Owen, 2006; Owen et al., 2006) experiments has accumulated that even patients diagnosed as being in a PVS can exhibit signs of cortical stimulus processing at different levels of complexity. We expected that the processing of affective prosody would also be present in some of these patients. Particularly, on the basis of previous lesion studies (e.g., Ross et al., 1998), better results may be expected in patients with an intact RTL. 
Table 1

Patient Data

\begin{tabular}{|c|c|c|c|c|c|c|c|c|c|}
\hline Initials & $\begin{array}{c}\text { Age } \\
\text { (years) }\end{array}$ & Gender & Diagnosis & Etiology & $\begin{array}{l}\text { Duration } \\
\text { (months) }\end{array}$ & BAEPs & $\begin{array}{c}\text { Scan } \\
\text { Method }\end{array}$ & Main Lesion & $\begin{array}{c}\text { RTL } \\
\text { Damage }\end{array}$ \\
\hline A.O. & 37 & $\mathrm{~F}$ & GBS & & 70 & normal & no & & \\
\hline J.B. & 52 & M & ALS & & 79 & normal & no & & \\
\hline J.W. & 55 & M & ALS & & 83 & normal & no & & \\
\hline B.K. & 64 & M & PVS & $\mathrm{SAH}$ & 4 & normal right & CT & Diffuse cortical atrophy & Yes \\
\hline G.R. & 35 & M & PVS & TBI & 2.5 & normal & CT & Frontotemporal left & No \\
\hline H.S. & 20 & M & PVS & TBI & 2 & normal & CT & Frontotemporal right & Yes \\
\hline K.B. & 63 & M & PVS & stroke & 1.5 & normal & CT & Thalamus, capsula interna & No \\
\hline L.M. & 35 & M & PVS & $\mathrm{SAH}$ & 8 & normal right & CT & Diffuse cortical atrophy & Yes \\
\hline M.R. & 37 & M & PVS & anoxia & 9 & normal & CT & Frontotemporal left & No \\
\hline N.J. & 18 & M & PVS & TBI & 2.5 & normal & MRT & Parietooccipital bilateral & No \\
\hline P.C. & 33 & $\mathrm{~F}$ & PVS & TBI & 11 & normal right & CT & Temporal left & No \\
\hline R.G. & 43 & $\mathrm{~F}$ & PVS & anoxia & 2 & normal & CT & Diffuse cortical atrophy & Yes \\
\hline R.J. & 38 & $\mathrm{~F}$ & PVS & anoxia & 3 & normal & CT & Diffuse cortical atrophy & Yes \\
\hline R.T. & 18 & M & PVS & TBI & 4 & normal left & CT & Frontotemporal right & Yes \\
\hline R.U. & 19 & $\mathrm{~F}$ & PVS & stroke & 26 & normal & MRT & Frontal, temporal, parietal right & Yes \\
\hline V.G. & 54 & M & PVS & SAH & 6 & normal & CT & Frontotemporal bilateral & Yes \\
\hline W.J. & 55 & M & PVS & TBI & 3 & normal & $\mathrm{CT}$ & Diffuse cortical atrophy & Yes \\
\hline W.U. & 45 & M & PVS & TBI & 7 & normal & MRT & Parietotemporal left & No \\
\hline B.U. & 50 & $\mathrm{~F}$ & MCS & $\mathrm{SAH}$ & 2 & normal & CT & Frontal bilateral, temporal right & Yes \\
\hline G.E. & 68 & M & MCS & anoxia & 5.5 & normal & CT & Diffuse cortical atrophy & Yes \\
\hline H.A. & 53 & M & $\mathrm{MCS}$ & anoxia & 6 & normal & CT & Diffuse cortical atrophy & Yes \\
\hline H.K. & 32 & M & MCS & TBI & 108 & normal & MRT & Diffuse subcortical & No \\
\hline H.T. & 54 & $\mathrm{~F}$ & MCS & anoxia & 5 & normal & CT & Diffuse cortical atrophy & Yes \\
\hline J.M. & 30 & M & $\mathrm{MCS}$ & $\mathrm{SAH}$ & 4 & normal left & CT & Frontal bilateral & No \\
\hline L.A. & 55 & M & MCS & anoxia & 2 & normal left & MRT & Diffuse cortical atrophy & Yes \\
\hline O.T. & 67 & M & MCS & stroke & 2 & normal right & CT & Frontotemporal left & No \\
\hline R.F. & 24 & $\mathrm{~F}$ & MCS & TBI & 45 & normal & MRT & Frontal left, posterior bilateral & No \\
\hline S.B. & 59 & M & MCS & $\mathrm{SAH}$ & 8 & normal & CT & Diffuse cortical atrophy & Yes \\
\hline S.I. & 50 & $\mathrm{~F}$ & $\mathrm{MCS}$ & $\mathrm{SAH}$ & 4.5 & normal & CT & Diffuse cortical atrophy & Yes \\
\hline T.Y. & 27 & M & MCS & TBI & 57 & normal & CT & Mostly thalamic bilateral & No \\
\hline
\end{tabular}

Note-ALS, amyotrophic lateral sclerosis; GBS, Guillain-Barré syndrome; MCS, minimally conscious state; PVS, persistent vegetative state; $\mathrm{SAH}$, subarachnoidal hemorrhage; TBI, traumatic brain injury; CT, computer tomography; MRT, magnetic resonance tomography; RTL, right temporal lobe. Boldface initials are those of patients who exhibited significant responses to prosodic stimuli.

The study was approved by the ethical committee of the University of Tübingen Medical School. Patients were examined, with the informed consent of their legal representatives.

\section{METHOD}

\section{Subjects}

Eight men and 8 women, age range $26-40$ years, took part in the MEG experiment. All subjects were right-handed. None had a history of any neurological or psychiatric disease. All subjects were paid $€ 8 / \mathrm{h}$.

A total of 29 patients with severe disorders of consciousness were examined; the data of 2 patients were dismissed due to excessive movement artifacts. The remaining group consisted of patients in PVS or minimally conscious state (MCS). ${ }^{1}$ Inclusion criteria for this group were: age $>16$; normal brainstem auditory evoked potentials (BAEPs) at least on one side with possibly delayed, but not absent, BAEPs on the other side; no flat EEG; and no diffuse delta waves in the EEG. All patients were examBined during waking. The cortical N1 component of the auditory evoked potentials was present in all of them.

Additionally, 3 patients with severe motor disability were examined, 2 of them totally paralyzed (including a complete gaze paralysis), and the 3rd with tetraplegia and speech paralysis. The data of all patients are summarized in Table 1. Below we describe in more detail the data of those patients whose electrophysiological data will be presented in Figures 4 and 5 .

1. Patient K.B.: male, 63, diagnosed as PVS after a parenchymal hemorrhage with extensive lesions in the thalamus and capsula in- terna. Coma duration was 12 days. EEG examination on Day 50 (when the prosody experiment was carried out) showed regular symmetrical fast theta oscillations of $6-7 \mathrm{~Hz}$, without a response to light, normal BAEPs and slightly delayed somatosensory evoked potentials (SSEPs).

2. Patient J.M.: male, 30, admitted at the neurosurgical hospital with a subarachnoidal hemorrhage from the ramus communicans anterior. Angiographic examination demonstrated an aneurysm in this artery. An attempt to close this aneurysm with endovascular coils resulted in a transient closure of both anterior cerebral arteries, leading to a severe generalized swelling. Computer tomography (CT) showed severe malresorptive hydrocephalus. Therefore, a ventriculoperitoneal shunt was installed, resulting in the improvement of liquor circulation. Coma duration was 24 days. EEG examination took place on Day 131. The patient was awake and capable of shorttime visual fixation. The diagnosis was MCS or suspected PVS. The EEG was characterized by the predominant symmetrical theta rhythm, without a consistent response to stimulation. BAEPs and SSEPs were intact.

3. Patient M.R.: male, 37, survived brain anoxia brought on by prolonged cardiac arrest. He was in a coma for 3 weeks. CT demonstrated a diffuse atrophy of cortical gray matter, predominantly in the left frontal, temporal, and parietal lobes. The diagnosis was PVS. The prosody experiment was carried out on Day 294. The EEG was mainly characterized by theta activity at $5-6 \mathrm{~Hz}$, which was not suppressed by light. SSEPs were delayed and decreased in amplitude. BAEPs were slightly delayed on the right side and normal on the left side.

4. Patient J.B.: male, 52. Five years prior to participation in the present study, he was diagnosed with amyotrophic lateral sclerosis (ALS) with a pseudobulbar syndrome. Difficulties in swallowing and 
speech (dysarthria) dramatically increased within a few weeks after diagnosis. After 1.5 years, a paresis in the extremities developed, finally leading to complete paralysis. The patient was tracheostomized after acute respiratory failure. During the next 3 years he communicated using eye movements. He also was trained, with considerable success, to use a brain-computer interface (Kübler et al., 1999). After pneumonia and subsequent sepsis lasting for about 5 weeks, any communication abilities were lost. The patient was artificially ventilated and fed. The EEG demonstrated a regular alpha rhythm, reactivity to light stimulation, and normal BAEPs and SSEPs.

5. Patient J.W.: male, 55, had suffered from ALS for 7 years. The onset of the disease was marked by slowly developing weakness in the legs accompanied by paresthesias. This progressive weakness resulted in a complete paraplegia within 3 years, followed by a similar symptom development in the upper extremities. During the time of examination, the patient's status was characterized by tetraplegia with hypotonia in the legs and hypertonia and hyperreflexia in the arms. Breathing was spontaneous, but speech and swallowing were impossible. The patient communicated using eye movements, mimicry, and vocalizations. No abnormality was found in the rest EEG or in sensory evoked potentials.

6. Patient A.O.: female, 37, suffered from chronic polyradiculoneuropathy with Guillain-Barré syndrome (GBS) for almost 6 years. Her clinical condition and the results of her first ERP examination have been reported elsewhere (Kotchoubey, Lang, Bostanov, $\&$ Birbaumer, 2003). Here, a result of the second examination is presented, 8 months after the first one. The patient was completely unresponsive, with eyes closed and depressed muscle tone. The EEG showed an occipital alpha rhythm of very low amplitude ( $8 \mathrm{~Hz}, 5-10 \mu \mathrm{V})$, decreasing with stimulation. BAEPs and SSEPs were completely normal. As with J.B., no communication using eye movements was possible.

\section{Procedure}

Five emotional vocalizations were presented, four of them being exclamations of joy: "Yeeh!," "Heey!," "Wow!," and "Oooh!” A single exclamation of woe, "Oooh!," served as a deviant stimulus. The duration of both "Ooohs" was $840 \mathrm{msec}$; that of the other joyful stimuli, 750, 800, and $870 \mathrm{msec}$, respectively. All five stimuli had the same occurrence frequency of $20 \%$. The vowel /o/ was purposely chosen for both the sad exclamation and one of the joyful exclamations. The stimuli were identical to those used in Bostanov and Kotchoubey (2004) and Kotchoubey, Lang, Bostanov, and Birbaumer (2003). In the former article, spectrograms are presented, and it was shown that the difference between the ERPs to "Oooh!" (woe) and Oooh!" (joy) was the same as that between "Oooh!" (woe) and the average of all joyful stimuli, thus demonstrating that this difference cannot be attributed to a particular vowel. However, it would be incorrect to compare the sad stimulus only with "Oooh!" (joy), because different standards matched different features of the deviant. The sad exclamation was adjusted so that it was close to the mean of the four joyful exclamations in terms of F0 and average intensity. Control experiments (which cannot be reported here in detail) showed that whenever the deviant, whether an emotional or tonal stimulus, differed from standards in a simple acoustical property such as F0 or intensity, it elicited a completely different response, dominated by a parietal P300. Only emotional deviants matched to standards - at least with respect to the perceived pitch and loudness-elicit a pattern presented in Figure 1.

All exclamations were uttered by a male speaker who was not a professional actor, and were recorded digitally at a $22-\mathrm{kHz} / 16$-bit sampling rate. The sounds had been tested on several groups of young healthy individuals in Germany, France, England, Italy, and Israel, with the recognition rate being $92 \%-95 \%$ in all groupsexcept the French, whose recognition rate was $80 \%$. During the experiment, each of the five stimuli occurred 60 times in a randomized sequence of 300 sounds binaurally presented at a rate of $1 \mathrm{stimulus} / 1.1 \mathrm{sec}$. All healthy subjects in the present experiment reported that they recognized one (infrequent) woe stimulus among several joyful stimuli.

All subjects were told to avoid movements and to listen to the stimuli. They were not instructed to make an overt or covert response to any stimulus, mainly because the procedure was designed for patients who cannot make any response (see Bostanov \& Kotchoubey, 2004; Kotchoubey et al., 2005; Neumann \& Kotchoubey, 2004). Additionally, an active instruction, such as making a motor response or mental count, might activate processes of "perceptual closure" (e.g., Verleger, 1988), resulting in a P300 to the deviant.

\section{Data Acquisition and Analysis}

Healthy subjects. MEG was recorded from 151 first-order magnetic gradiometers (CTF Inc., Vancouver, BC) and was digitized at $250 / \mathrm{sec}$. The subject's head position was determined using localization coils at the nasion and preauricular points and repeatedly controlled after the end of the experimental procedure. Artifactual trials (no more than five per subject) were defined according to the amplitude criterion $>1.3 \mathrm{pT}$ in frontal channels and were dismissed. The data were subdivided into epochs from -100 to $+1,000 \mathrm{msec}$ around stimulus onset. After this, they were digitally filtered with a high pass of $0.5 \mathrm{~Hz}$ and a low pass of $40 \mathrm{~Hz}$. Difference fields were computed by subtracting the waveforms produced by the sad exclamation from the mean waveforms produced by the joyful exclamations.

The mean amplitudes of event-related magnetic fields were determined for each channel in the intervals from 200 to $300 \mathrm{msec}$ and from 300 to $500 \mathrm{msec}$, which corresponds approximately to the N300 and the following slow negative component. Additionally, an interval of $80-140$ msec (N1) was measured. The absolute values of these amplitudes (regardless of the sign) were compared between joyful and sad exclamations in each channel, using a $t$ test. Furthermore, means were calculated for the following groups of sensors: frontal right, frontal left (16 sensors each); central right, central left (16 sensors each); parietal right, parietal left ( 9 sensors each); anteriotemporal right, anteriotemporal left (10 sensors each); and posteriotemporal right, posteriotemporal left (11 sensors each). The sensors at the midline were excluded. A repeated measures ANOVA was then performed with factors of region (five levels), side (two levels: right vs. left) and stimulus (five levels), and time window (two levels: 200-300 vs. 300-500 msec). The last factor was not included in the ANOVA for N1. When appropriate, Greenhouse-Geisser epsilon $(\varepsilon)$ correction for nonsphericity was applied. When the main effect of the factor stimulus or its interactions were significant, $t$ tests were conducted to compare responses to individual stimuli pairwise.

Patients. EEG was recorded using nine sintered $\mathrm{Ag} / \mathrm{AgCl}$ electrodes attached at scalp positions F3, Fz, F4, C3, Cz, C4, P3, Pz, and $\mathrm{P} 4$, according to the 10-20 system. Two mastoid electrodes connected via a $15-\mathrm{k} \Omega$ shunt served as reference. Two vertical (above and below one eye) and horizontal ocular electrodes (at the outer corners of both eyes) were used to record the electrooculogram (EOG). The signals were digitized at $512 / \mathrm{sec}$ and filtered with a high-pass filter of $0.3 \mathrm{~Hz}$ and a low-pass filter of $70 \mathrm{~Hz}(12 \mathrm{~dB} /$ octave). Additionally, a notch filter was set around $50 \mathrm{~Hz}$. Epochs were chosen from $100 \mathrm{msec}$ before to $1 \mathrm{sec}$ after stimulus onset. A regression procedure (Gratton, Coles, \& Donchin, 1983) was employed to correct blink and eye movement artifacts. The remaining artifacts (1-3 trials per patient/condition) were dismissed according to the $\pm 150 \mu \mathrm{V}$ amplitude criterion.

For statistical analysis, the ERPs were first averaged for each individual patient across all responses, irrespective of condition: the so-called total average, which was then wavelet transformed using the continuous wavelet "Mexican Hat." In this total-average scalogram, wavelet measures for the N300 were identified as described in Bostanov and Kotchoubey (2004). Thus defined, N300 amplitudes were then measured in each single trial and grouped into five conditions according to the five stimuli presented. The following statistical evaluation was carried out by means of ANOVAs with topography 
(nine electrodes) as a repeated measures factor and stimulus (two levels, with each stimulus being compared with all the remaining stimuli) as a "between-trial" factor. The alpha level was set at .05 , one-tailed, because a one-sided hypothesis (i.e., the potential would be more negative to deviants than to standards) was tested.

\section{RESULTS}

\section{Healthy Subjects}

The time course of MEG responses to emotionally positive and negative exclamations is shown in selected channels in Figure 2. A comparison between Figures 1 and 2 reveals similarity of the waveforms recorded in EEG and MEG. The most prominent component common to all responses and channels was the N1 with a latency of about 100 msec. As shown in Figure 3, this component was localized in the temporal lobes of both hemispheres. Moreover, the difference map (Figure 3C) did not show substantial differences between the two conditions. This visual impression was further supported by the statistical analysis. Of the total of 151 MEG channels, a larger absolute N1 amplitude to sad than to joyful stimuli was found in 70 channels; the opposite was true for 81 channels. The ANOVA showed that neither the main effect of stimulus nor its interactions were significant; however, as expected, the main effect of region was highly significant $[F(4,60)=7.92, p<.001, \varepsilon=.718]$.

In contrast to the $\mathrm{N} 1$, the subsequent negativities appeared to differ between standards and deviants. In the ANOVA, the main effect of stimulus $[F(4,60)=4.97, p=$ $.007, \varepsilon=.645]$ was significant in both the $200-300 \mathrm{msec}$ window $[F(4,60)=3.85, p=.037, \varepsilon=.454]$ and the $300-500$ msec window $[F(4,60)=5.64, p=.01, \varepsilon=$ $.462]$. Obviously, the activity differed among the regions [main effect of region: $F(4,60)=19.44, p<.001, \varepsilon=$ $.718]$. More importantly, the stimulus effect also varied as a function of region [region $\times$ stimulus interaction: $F(16,240)=6.71, p=.001, \varepsilon=.193]$. Although this interaction was significant in both time windows $[F(16,240)=$ $3.20, p=.019, \varepsilon=.263$; and $F(16,240)=3.96, p=.007$, $\varepsilon=.249$, for 200-300 and 300-500 msec, respectively], the triple interaction between region, stimulus, and time window also attained significance $[F(16,240)=2.02, p=$ $.048, \varepsilon=.321]$.

No effect containing the factor of side approached significance. Therefore, in the further analysis, the data were collapsed over the symmetric regions in the two hemispheres. In the 200- to 300-msec window, the response to the deviant was generally larger than that to the standards "Yeeh!" $(t=4.85, p<.001)$ and "Heey!" $(t=2.19, p=$ $.044)$. Particularly over the parietal regions, the deviant response was larger than responses to "Yeeh!" $(t=5.49$, $p<.001)$ and "Heey!" $(t=4.25, p=.004)$, and the difference to joyful "Oooh" approached significance $(t=1.87$, $p=.081)$. The same pattern was found for the posteriotemporal cortex (deviant minus "Yeeh!": $t=10.44, p<$ .001 ; deviant minus "Heey!": $t=7.05, p<.001$; deviant minus joyful "Oooh!": $t=1.94, p=.068$ ).

In the 300-500-msec window, the deviant elicited a larger response than did "Yeeh" $(t=8.81, p<.001)$,
"Wow" $(t=3.70, p=.002)$, and joyful "Oooh" $(t=2.35$, $p=.033)$. Particularly, significant differences were obtained for central (deviant minus "Yeeh!": $t=3.08, p=$ .008 ; deviant minus "Wow!": $t=2.69, p=.017$ ), anteriotemporal (deviant minus "Yeeh!": $t=7.19$; deviant minus "Wow!": $t=7.22$; deviant minus joyful "Oooh!": $t=6.81$, all $p \mathrm{~s}<.001$ ), posteriotemporal (deviant minus "Yeeh!": $t=6.08$; deviant minus "Wow!": $t=5.50$; deviant minus joyful "Oooh!": $t=5.93$, all $p$ s $<.001$ ), and frontal (deviant minus "Yeeh!": $t=3.50, p=.003$; deviant minus "Oooh!": $t=1.93, p=.073$ ) regions. No pairwise comparison between responses to any two joyful stimuli attained significance at any region.

Thus, from the analysis above, it appears that the difference between standards and deviants had a more anterior distribution in the 300 - to 500 -msec time window than in the 200- to 300-msec time window. To further test this impression, we built new sensor groups according to the distribution of the magnetic fields apparent in Figure 3. Specifically, the anterior group included 50 sensors: MLC11, MLC12, MLC13, MLC14, MLC15, MLC21, MLC22, MLC23, MLC24, MLC31, MLC32, MLC33, MLC41, MLC42, MLC43, MLT21, MLT11, MLT31, MLT22, MLT41, MLT12, MLT32, MLT23, MLT13, MLT42, and the symmetrical sensors on the right side, with the nasion-inion coordinates from -0.21 to +0.63 , where nasion $=+1$ and inion $=-1$. The posterior group included 40 sensors: MLP11, MLP12, MLP13, MLP21, MLP22, MLP31, MLP32, MLP33, MLP34, MLT33, MLT24, MLT14, MLT43, MLT34, MLT25, MLT15, MLT44, MLT16, MLT35, MLT26, and the symmetrical sensors on the right side, with the nasion-inion coordinates from -0.27 to -0.72 . An ANOVA was then performed with factors of anterior/posterior (AP: two levels), stimulus, and time window (two levels). Because the responses to standard stimuli did not differ, the stimulus factor was simply taken as having two levels, standards versus deviants. The ANOVA revealed a significant triple AP $\times$ stimulus $\times$ time window interaction $[F(1,15)=$ $6.14, p=.026]$. Post hoc $t$ tests indicated a significantly larger difference between standards and deviants over anterior sensors in the later, as compared with the earlier, time window $(t=-2.77, p=.014)$. The opposite trend was found for posterior sensors $(t=2.12, p=.051)$.

McCarthy and Wood (1985) demonstrated that condition $\times$ topography interactions can be significant even if the same neural generator is active in different conditions, because the ANOVA is based on the additivity assumption-whereas real electrophysiological effects are not additive. For example, if the generator doubles its activity in a Condition 2 instead of a Condition 1, the amplitude recorded by spatially close electrodes or sensors increases more than does that recorded by remote electrodes or sensors, possibly leading to an interaction effect that might be erroneously interpreted as evidence for different generators in different conditions. McCarthy and Wood suggested several techniques for correction of such artificial interactions. Importantly, however, in the above example the amplitudes would increase at all sensors. This 
Left Hemisphere
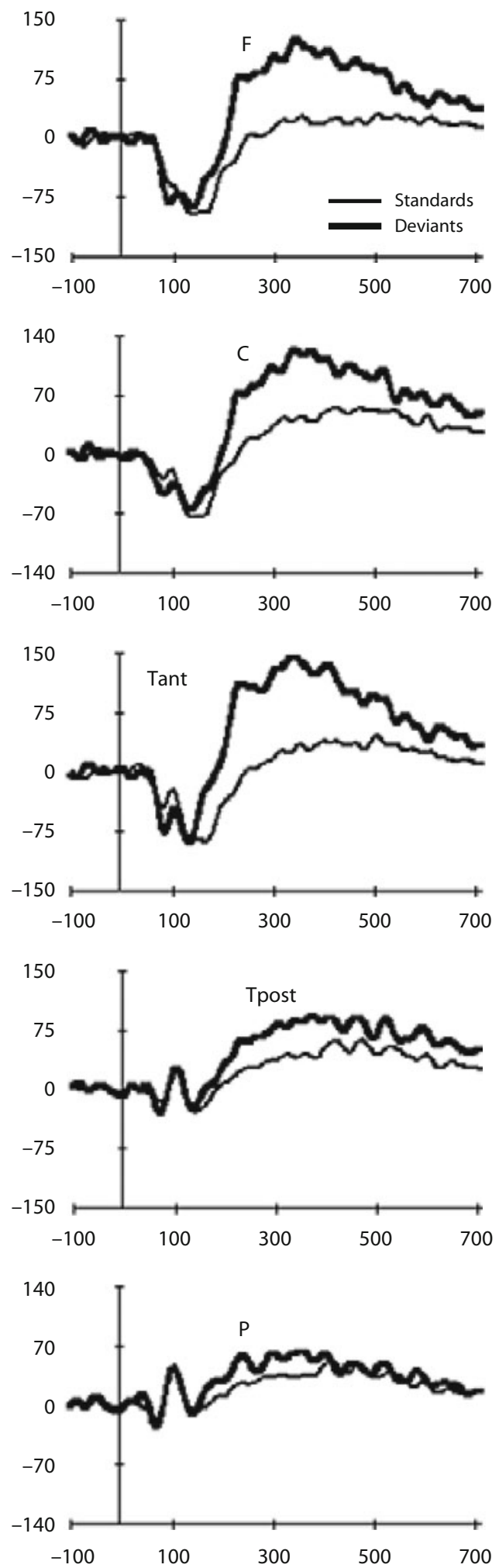

Right Hemisphere
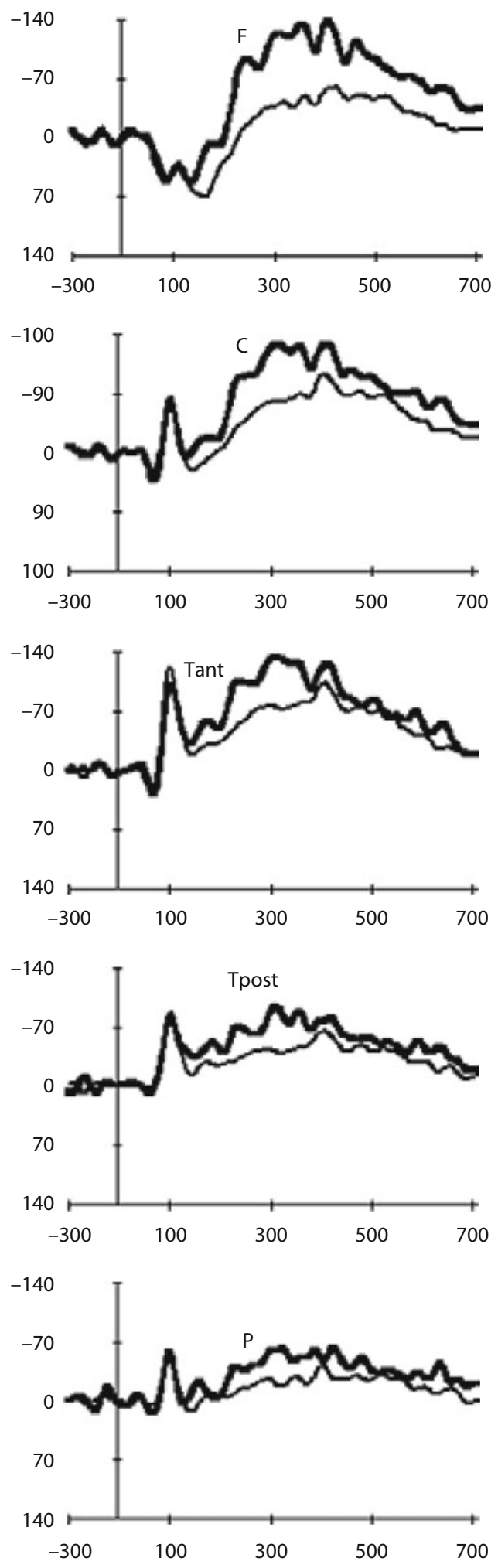

Figure 2. Time course of MEG responses to standards (joyful screams, thin line) and deviants (sad screams, bold line) is exemplified at five symmetrical recording points over each hemisphere, which correspond approximately to the following 10-20 positions (from top to bottom): F3 and F4; C3 and C4; T3 and T4; T5 and T6; P3 and P4. Amplitude in femtotesla (fT), time in milliseconds. Note the opposite polarity of the amplitude scales for the left and right hemispheres. 

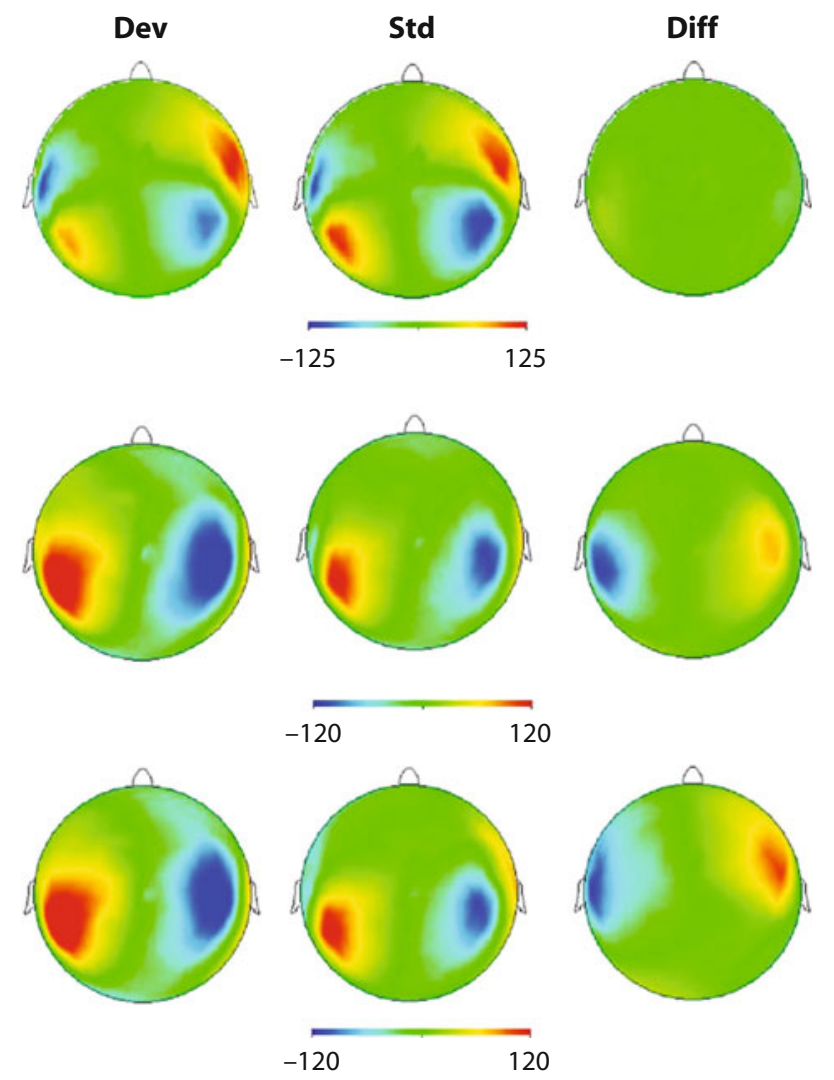$$
120
$$

Figure 3. Surface distribution of magnetic fields for the time windows 80-140 msec (N1, top row), 200-250 msec (N300, middle row), and 300-500 msec (slow activity, bottom row). Dev, deviant stimuli; Std, standard stimuli; Diff, difference deviant minus standard. The color scale in $\mathbf{f T}$.

is an "ordered" interaction, in which all levels of the factor A (i.e., all sensor sites) change in the same direction, albeit in different degrees. The present data give an opposite case of an "unordered interaction," because the difference between standards and deviants in the earlier time window increases in the posterior direction, whereas in the later time window it increases in the anterior direction. In this situation, a nonadditivity correction is not necessary (e.g., Scheffé, 1959).

\section{Patients}

Significant differences between emotionally positive and negative stimuli were found in 6 of the 27 patients with severe brain damage. The corresponding significance values were $F(1,298)=21.56, p<.001 ; F(1,290)=9.91$, $p=.001 ; F(1,295)=4.36, p=.019 ; F(1,297)=3.32$, $p=.035 ; F(1,298)=3.35, p=.034$; and $F(1,298)=$ $3.11, p=.04$, one-tailed. When the group was split into those with $(n=15)$ and without $(n=12)$ a well-expressed damage to the RTL, the frequency of significant results was higher in the latter group than in the former $[42 \% \mathrm{vs}$. $\left.7 \% ; \chi^{2}(1)=4.7, p<.05\right]$. Figure 4 shows the data of the 3 patients whose history is described in the Method section above.
When ERPs were grouped regardless of their emotional tone, 108 individual comparisons were performed. A significant effect was found in 5 of them; this does not significantly differ from chance.

We also tried to group the patients according to factors other than the RTL lesion, but no classification yielded a significant result. Thus, no difference in significant responses to prosody was found between patients with the PVS versus MCS diagnosis $\left(\chi^{2}=0.39\right.$, n.s. $)$, between patients with traumatic rather than nontraumatic brain injury $\left(\chi^{2}=0.20\right.$, n.s. $)$, or between those with disease duration $<10$ months versus $>10$ months $\left(\chi^{2}=0.02\right.$, n.s.).

In both completely locked-in patients (J.B. [ALS] and A.O. [GBS]), ERPs significantly differentiated between sad and joyful exclamations $[F(1,298)=5.37, p=.011$, and $F=6.73, p=.005$, for J.B. and A.O., respectively]. A similar result was obtained with the severely paralyzed ALS patient, J.W. $[F(1,298)=7.16, p=.004]$. The waveforms of these patients are presented in Figure 5.

\section{DISCUSSION}

\section{Prosodic Responses in Patients and Controls}

The data demonstrate the reliability of the phenomenon previously described by Bostanov and Kotchoubey (2004): In an emotional oddball condition in which a single sad exclamation is presented with four equiprobable joyful exclamations, the sad deviant elicits a broadly distributed negativity starting (in healthy subjects) about $150 \mathrm{msec}$ poststimulus. The effect is clearly seen in both EEG and MEG. The significant effect, similar in latency and morphology, was also obtained in 6 out of 27 patients diagnosed with definite or probable PVS, as well as in all 3 patients with severe motor paralysis.

In the paralyzed patients, the intactness of speech comprehension (including prosody) might be expected, given that their diseases primarily affect the motor cortex and spinal cord (ALS) or the peripheral nervous system (GBS). However, numerous cognitive deficits have been described in ALS patients at both behavioral (Abe et al., 1997; Abrahams et al., 2000; Ludolph et al., 1992) and electrophysiological (Hanagasi et al., 2002; Paulus et al., 2002; Vieregge, Wauschkuhn, Heberlein, Hagenah, \& Verleger, 1999) levels - apart from their well-known motor deficits. These studies investigated patients at intermediate stages of the disease. It remains ultimately unknown what extent those dysfunctions may attain in the last stages of ALS (Kotchoubey, Lang, Winter, \& Birbaumer, 2003; Lakerveld, Kotchoubey, \& Kübler, 2008; Strong, Grace, Orange, \& Leeper, 1996). As regards Patient A.O., she had been completely locked in for more than 3 years, which also might result in secondary deficits in cognitive functions. Nevertheless, significant differential responses to emotional deviants were recorded in each of the 3 patients.

In the patients with severe brain damage, a significant response was obtained in $22 \%$, a high proportion given these patients' behavioral nonresponsiveness and their di- 
K.B.
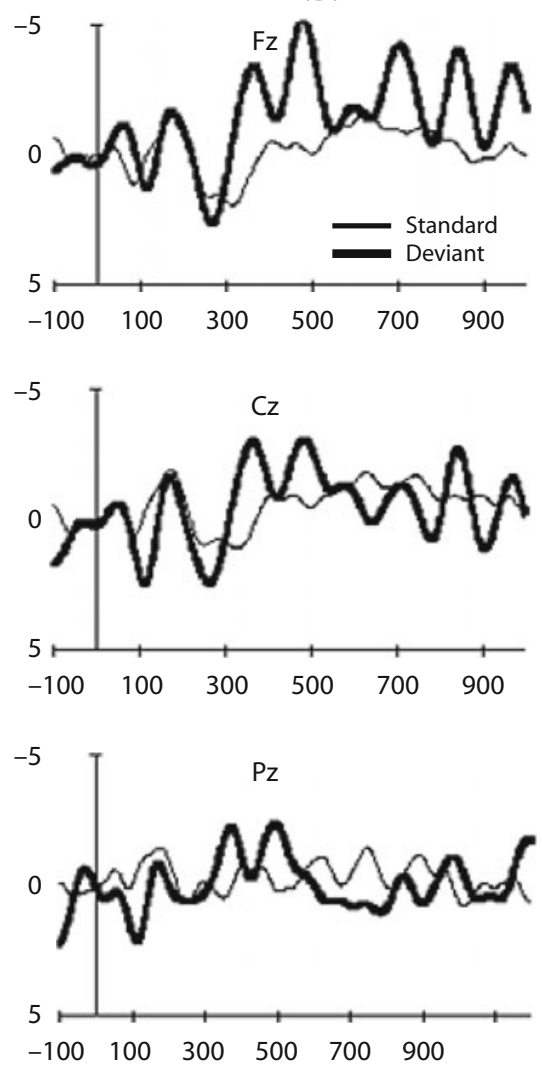

M.R.
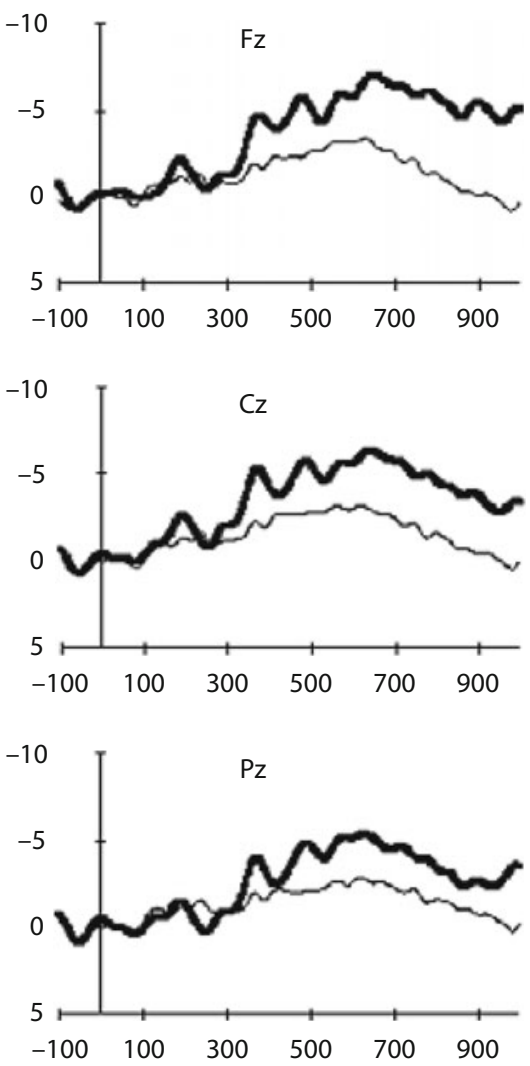

J.M.

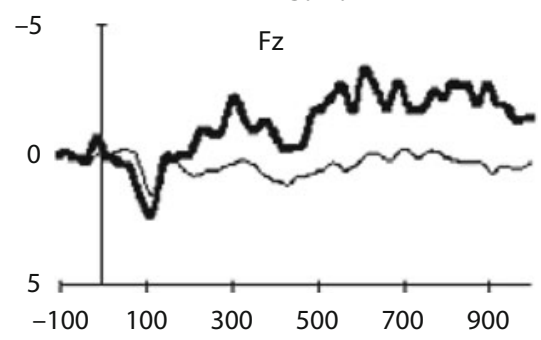

Figure 4. ERPs of two patients diagnosed as being in a persistent vegetative state (K.B. and J.M.) and patient M.R., who was in a minimally conscious state. Negativity is up. Only midline recording sites are shown. Amplitude is in $\mu \mathrm{V}$ (different scales for different patients, according to their individual EEG size); time is in milliseconds. The difference between standards (thin line) and deviants (bold line) was significant in each of these patients. Note that although the patients' waveforms are not identical to the averaged waveform of control subjects presented in Figure 1, they also exhibit the two critical components: the N300 and the late slow negativity to deviant stimuli. The former is delayed compared with control subjects, which may be why the two merged, as with patient M.R.

agnosis, the most severe that exists in neurology (Jennett, 2002). Of course, these data should be interpreted with caution. A positive finding demonstrates that the brain is able to discriminate affective screams, but not that the patient consciously experiences the emotional content of the screams. There is MEG evidence that the brain of human newborns in quiet sleep can differentially respond to the affective features that the human voice can be recognized by (Sambeth, Ruohio, Alku, Fellman, \& Huotilainen, 2008). Monkeys respond very adequately to emotional screams of their conspecifics. This does not imply that we can now make wide-ranging inferences about subjective emotional experience in newborns and monkeys.

Also, the lack of a significant response does not prove an inability to recognize prosody. As discussed at length elsewhere (Kotchoubey et al., 2005; Neumann \& Kotchoubey, 2004), all neuroscience assessment techniques are prone to false negatives - that is, to miss a response despite a preserved underlying function (see also Owen et al., 2006). However, the high percentage of positive findings indicates that the proposed oddball paradigm with brief emotional exclamations can be used in a clinical setting for the assessment of the perception of emotional prosody.

\section{Topography}

The topographic distribution of the response to deviant affectively negative stimuli, obtained by means of a 151-channel MEG, does not indicate a distinct cerebral generator. Dipole modeling did not result in a clearly localizable source of the N300; rather, the projected dipole was localized in the depth of the head, which is highly improbable, given the biophysical features of the MEG signal. This probably results from a large number of broadly distributed, perhaps overlapping sources. It cannot be ruled out that a better result might be obtained using another imaging technique (e.g., fMRI) more suitable for an analysis of the activity in deeper brain structures and whose data, in contrast to MEG data, would not depend on the orientation of the electromagnetic forces.

Figure 3 shows a contrast between the N1 component, with its clearly bilateral temporal sources on the one hand and the broad distribution of the following negativities on the other. The distribution of the N1 magnetic fields is virtually identical to that found in other studies (e.g., Lütkenhöner \& Steinsträter, 1998; Pantev et al., 1995). The $\mathrm{N} 1 \mathrm{~m}$ component does not vary as a function of stimulus condition. 
J.B.
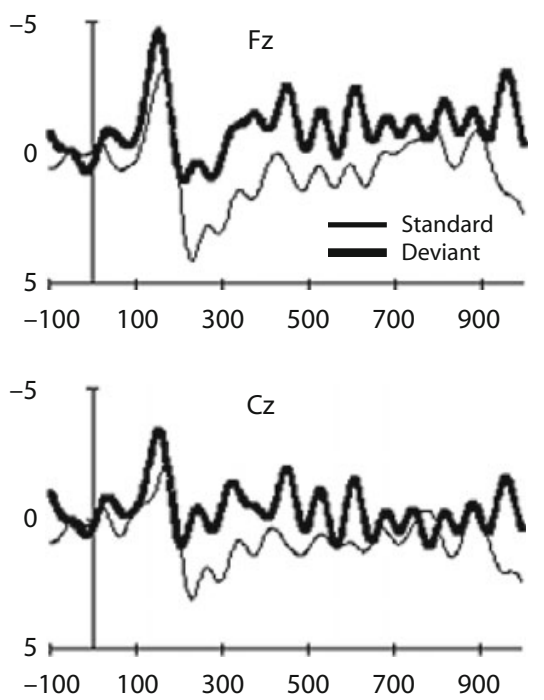

$-5$

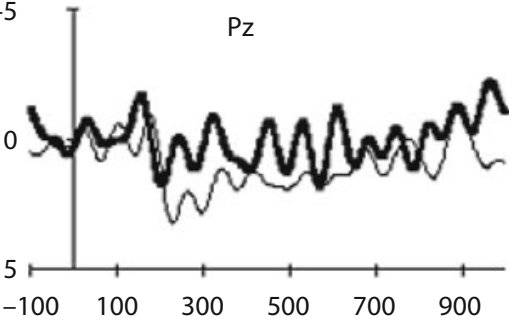

A.0.
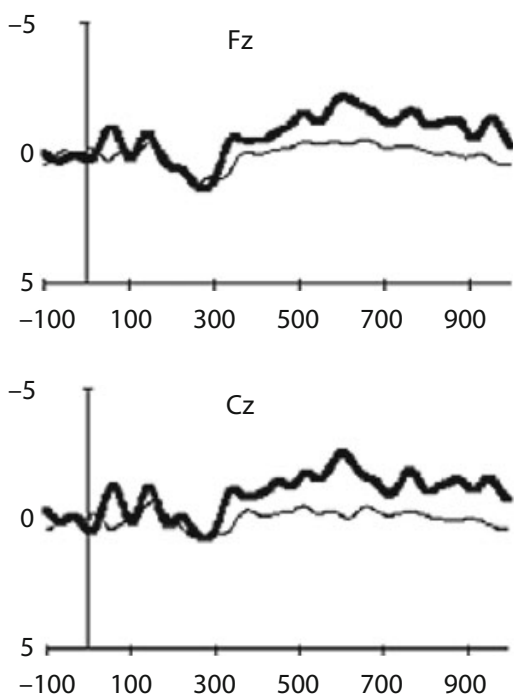

$-5$

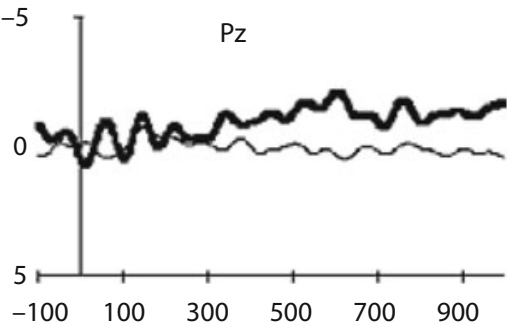

J.W.

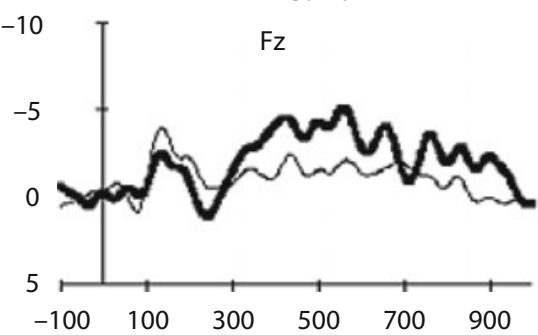

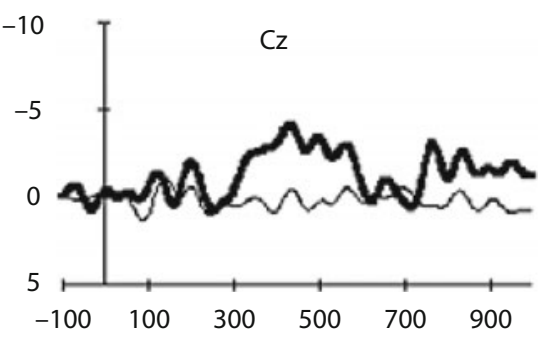

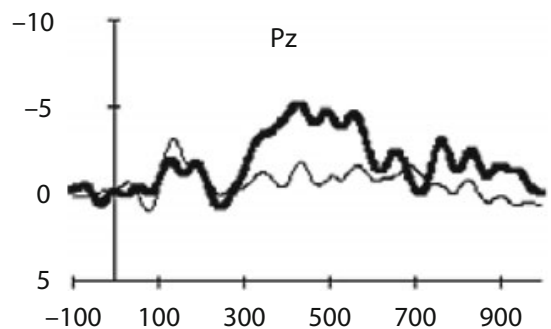

Figure 5. The same as Figure 4, except for severely paralyzed patients J.B., A.O., and J.W.

Although the application of the MEG did not result in the expected spatial localization of the N300, it was nonetheless useful in two important respects. First, it appears that this component is not a member of the MMN family. The MMNm has frequently been investigated in our group (e.g., Kaiser \& Lutzenberger, 2001; Kaiser, Lutzenberger, \& Birbaumer, 2000; Kaiser, Lutzenberger, Preissl, Ackermann, \& Birbaumer, 2000), as well as by many other scholars (e.g., Mathiak, Hertrich, Lutzenberger, \& Ackermann, 1999; Shtyrov et al., 1998; Thönnessen et al., 2008; Tiitinen, May, Reinikainen, \& Näätänen, 1994). Even though the results of these studies are not identical (which is not surprising, taking into account the huge variability among MMN paradigms), they converge on a well-defined dipole localized at, or in the vicinity of, the temporal planes (Mathiak et al., 2002; Näätänen \& Winkler, 1999).

Since most typical MMN studies use several hundred deviants, one might ask whether increasing the number of deviants would result in more typical MMN topography. This supposition, however, is implausible, since many clinical studies (e.g., Kawakubo et al., 2007; Korpilahti et al., 2007; Thönnessen et al., 2008, "traditional condition") and nonclinical studies (e.g., Pulvermüller et al., 2008; Röttger, Schröger, Grube, Grimm, \& Rübsamen, 2007; Ruusuvirta, Huotilainen, \& Näätänen, 2007), including MEG studies (e.g., Lipski \& Mathiak, 2007;
Mathiak et al., 1999), use about 100 deviants or even fewer (e.g., Mueller, Brehmer, von Oertzen, Li, \& Lindenberger, 2008; Schröger \& Wolff, 1997; Srinivasan \& Baijal, 2007), which does not prevent important findings. Kane, Curry, Butler, and Cummins (1993) and Kane et al. (1996), using only 32 deviants in coma patients, were the first to discover the high positive predictive value of the MMN regarding the outcome of acute coma, a finding later supported by numerous large studies (see a meta-analysis by Daltrozzo, Wioland, Mutschler, \& Kotchoubey, 2007). The same was found in chronic disorders of consciousness using 70 deviants (Kotchoubey et al., 2005). Although a small number of deviants (mostly enforced by the necessity of short-time clinical investigations) decreases the signal-noise ratio, it does not result in a radical change of wave topography. Thus the distributions of magnetic fields shown, for example, by Kaiser, Lutzenberger, Preissl, et al. (2000, Figure 4), Mathiak et al. (1999, Figure 2), and Thönnessen et al. (2008, Figure 1) are strikingly similar, notwithstanding different MMN procedures and different numbers of trials, whereas our Figure 3 is clearly at odds with all of them.

Second, although visual inspection of the EEG data indicated a difference in scalp distribution between the N300 and the subsequent slow negative deflection, the expected condition $\times$ topography interaction was far from significant. In contrast, the MEG data allowed us 
to disentangle the two components, although both distinguished between emotionally positive standards and emotionally negative deviants. Whereas the N300 had a more posterior distribution, the subsequent slow component was frontocentral. Taking into account the remaining uncertainty about the generators of these components, it would be incautious to claim that those generators were different. Even the same generators might produce dipoles of a different orientation, thereby resulting in a different topography. Nevertheless, a significant change of dipole orientation, like a significant change in dipole structure, also indicates a change in processing; we may therefore assume that deviants in this experiment elicited at least two different, albeit overlapping, processes.

\section{Comparison With Other Negativities}

Given the lack of evidence of similarity between the N300 and the MMN, two other ERP components may be suggested as possible analogues of the response to prosodic mismatch: the N400 to semantic mismatch and the "phonological mismatch negativity" (PMN; Connolly, Phillips, Stewart, \& Brake, 1992; Connolly, Service, D'Arcy, Kujala, \& Alho, 2001). As regards the PMN, it has a latency close to the present N300 and has been proposed to reflect an obligatory mechanism of phonological processing (e.g., Newman \& Connolly, 2004). However, the origin of the PMN is clearly related to left-hemispheric speech areas. Two EEG studies using current source density analysis (Connolly et al., 2001) and BESA (D'Arcy, Connolly, Service, Hawco, \& Houlihan, 2004) indicated left-hemispheric sources, probably in Broca's area and the inferior parietal lobe. Using MEG, Kujala, Alho, Servece, Ilmoniemi, and Connolly (2004) obtained a distinct response in the left (and in a minority of subjects, also in the right) temporal lobe, localized anterior to the earlier N1 component and the later N400.

As regards the N400, imaging and lesion studies indicate its critical dependence on the temporal, inferior frontal and inferior parietal regions on the left side (for reviews of this and of the difference between lesion and imaging data, see Van Petten \& Luka, 2006). However, these sources are not unequivocally manifested in electrophysiological data obtained with the MEG or high-density EEG. Whereas some experiments resulted in well-defined dipoles in the left frontal and temporal lobes (Halgren et al., 2002; Karniski, Vanderploeg, \& Lease, 1993; Mäkelä, Mäkinen, Nikkilä, Ilmoniemi, \& Tiitinen, 2001), others yielded more symmetrical (Helenius et al., 2002), sometimes very broad scalp distributions (Brandeis, Lehmann, Michel, \& Mingrone, 1995; Curran, Tucker, Kutas, \& Posner, 1993; Haan, Streb, Bien, \& Rösler, 2000; Johnson \& Hamm, 2000; Mäkelä et al., 2001; Nobre \& McCarthy, 1994; Rösler, Streb, \& Haan, 2001). One group even obtained a right temporal generator of the semantic N400 (Nakagome et al., 2001). An MEG study of an N400 related to linguistic prosody resulted in a broad distribution without the expected right-side asymmetry (Hayashi et al., 2001). Furthermore, it was shown that N400 topography strongly depends on subtle features of stimulation (Mäkelä et al., 2001; Münte et al., 2001), and that the contributions of adjacent regions can have the opposite sign; that is, activity in response to congruent rather than incongruent words (Rossell, Price, \& Nobre, 2003) can increase in one region and decrease in the other. This makes it difficult to formulate strong predictions concerning the putative type of the N400 obtained in response to affective prosody violations.

To explore the issue on similarity versus difference between the "prosodic N300" and other negativities, further experiments are necessary in which several kinds of linguistic mismatch (phonological, prosodic, semantic) will be applied on the same material in a within-subjects design. As mentioned above, the interplay between prosody and semantics in generating an N400 to nonprimed words has already been shown with respect to both linguistic (e.g., Kerkhofs et al., 2007; Magne et al., 2005) and affective (e.g., Paulmann \& Kotz, 2008a, 2008b; Schirmer et al., 2002) prosody. Those paradigms could be modified in an attempt to elicit and compare both N400 and N300.

\section{Neurophysiology of Affective Prosody}

Earlier neuropsychological and imaging data, as well as dichotic listening experiments, have indicated a role of the right hemisphere - particularly the right superior temporal cortex - in the analysis of speech prosody (Buchanan et al., 2000; Grimshaw, Kwasny, Covell, \& Johnson, 2003; Perry et al., 2001; Ross et al., 1998). On the other hand, evidence is accumulating that the network underlying the recognition of affects from prosody involves other brain areas in addition to the RTL regions such as BA 22, including the dorsolateral and orbital frontal cortex, the frontal pole, the right insula, and the operculum (e.g., Adolphs et al., 2002; Breitenstein, Daum, \& Ackermann, 1998; Kotz et al., 2003; Plante, Holland, \& Schmithorst, 2006; Wildgruber et al., 2005). Data of Hornak, Rolls, and Wade (1996) and Hornak et al. (2003) demonstrated that frontal lesions at any side can considerably impair recognition of affective prosody. Also, the symmetrical left superior temporal gyrus can be active during prosodic perception, although this activity is usually smaller than in the right hemisphere (e.g., Ethofer, Anders, Wiethoff, et al., 2006; Humphries, Love, Swinney, \& Hickok, 2005). In summary, the data diverge considerably on the question of whether the pattern of brain activity is strongly right-lateralized (e.g., Mitchell, Elliott, Barry, Cruttenden, \& Woodruff, 2003; Wildgruber et al., 2005) or virtually symmetrical (e.g., Kotz et al., 2003). Among the factors possibly leading to different findings in different imaging studies are task requirements (e.g., paying attention to prosody or not); the amount and importance of semantic information delivered by the same stimuli that bear emotional information (e.g., words, pseudowords, exclamations); specific emotions, such as fear, that lead to particular activation patterns; basic physical stimulus features such as F0, intensity, and (in fMRI experiments) duration; 2 and finally, the nonspecific arousal elicited by stimuli (e.g., Mitchell et al., 2003; Sander et al., 2005; Schirmer et al., 2005; Wambacq et al., 2004; Wildgruber et al., 2005). A recent study even showed that the additional activation of the right middle superior temporal gyrus over its left tempo- 
ral counterpart in response to prosodic emotional stimuli disappears, if simple acoustical features and arousal are controlled (Wiethoff et al., 2008).

Despite these complicating factors, the extant data permit a suggestion that any component immediately related to the recognition of emotional prosody would reflect the activity of the right temporal cortex. Accordingly, the responses of PVS patients to emotional prosody were found to depend critically on the involvement of the RTL in the lesion. Nonetheless, the scalp distribution of magnetic fields did not show any particular activity of the RTL. In contrast to Bostanov and Kotchoubey (2004), this fact cannot be attributed to the insufficient spatial resolution of the EEG; thus, the N300 may be thought of as reflecting not the recognition of prosody per se, but rather, the following detection of a prosodic mismatch between the given stimulus and its affective context.

Recently, two neurophysiological models of processing of affective prosody have been proposed. One of them (Ethofer, Anders, Erb, et al., 2006), as a result of mathematical modeling on the basis of the authors' own data, suggests that the right temporal cortex ${ }^{3}$ serves as the input area for prosodic information, which is then conveyed to both frontal lobes for further processing. The other theory, based largely on a review of the literature (Schirmer \& Kotz, 2006), also assumes that, after an initial stage of basic spectrotemporal analysis in the primary and secondary auditory cortex, vocal emotional information is processed in the right hemisphere (superior temporal gyrus and sulcus) and then in frontal cortex for evaluative judgment concerning possible affective and semantic implications of emotional contents.

The present data are very much in line with both models. An initial analysis of basic auditory information is manifested in the temporal N1. After this, the emotional tone of a vocal stimulus (probably regardless of its semantic content or the lack thereof) is recognized on the basis of voice quality. As our patients' data show, this process requires the activity of right temporal regions. Like other (physical, conceptual) features of stimuli, prosodic features are continuously projected (anticipated) by the brain, and if the actual affective message is congruent with the anticipated one, it is "understood" at the emotional level of comprehension, and the process is closed. If it is incongruent, further cortical resources are mobilized to search for information necessary for the reestablishment of congruence. From this point of view, the present centroparietal N300 reflects this mobilization of resources for affective integration, just as the N400 reflects resource allocation for the following semantic integration (Holcomb, 1993; Silva-Pereyra et al., 1999). The next step, whose functional meaning is not completely clear (this might be the anticipation of future stimuli, or "higher-order evaluative processes"-Schirmer \& Kotz, 2006, p. 29), is related to the activity of the frontal cortex and manifested in the frontal slow wave that followed the more posterior N300. This activity was absent in a priming experiment in which stimuli were presented as pairs ("name of an emotionscream") rather than a stream of screams in the oddball experiments (Bostanov \& Kotchoubey, 2004).
Whereas Ethofer, Anders, Erb, et al.'s (2006) model does not specify the temporal parameters of the processing, Schirmer and Kotz (2006) first suggested that about $300 \mathrm{msec}$ are necessary for an analysis of affective prosody. Later on, however, Paulmann and Kotz (2008a) found ERP signs of affective prosodic processing even before $200 \mathrm{msec}$. The latter view is more in accordance with the present data, because the N300 onset can be as early as about $150 \mathrm{msec}$ and in no case later than $200 \mathrm{msec}$. Even though the hypothesized processes can overlap, the affective tone of the stimulus should at least partially be recognized by this time point. If this is true, emotional prosody can possibly be recognized within some 100-150 msec after the onset of an affective exclamation.

\section{AUTHOR NOTE}

We regret to note that Professor Lutzenberger died 2 days after the manuscript was accepted. The study was supported by the German Research Society (DFG). The authors thank Christoph Braun (University of Tübingen), Manfred Schneck (Münster Clinics Zwiefalten), Dieter Schmalohr (Youth Rehabilitation Center at Gailingen), Gerhard Mezger (Hospital for Neurorehabilitation, Wangen Allgäu), and Simone Lang (University of Heidelberg), as well as all our patients. Correspondence concerning this article should be addressed to B. Kotchoubey, Institute of Medical Psychology and Behavioral Neurobiology, University of Tübingen, Gartenstr. 29, 72074 Tübingen, Germany (e-mail: boris .kotchoubey@uni-tuebingen.de).

\section{REFERENCES}

Abe, K., Fujimura, H., Toyooka, K., Sakoda, S., Yorifuji, S., \& Yanagihara, T. (1997). Cognitive function in amyotrophic lateral sclerosis. Journal of the Neurological Sciences, 148, 95-100.

Abrahams, S., Leigh, P. N., Harvey, A., Vythelingum, G. N., GRISÉ, D., \& GoldsteIN, L. H. (2000). Verbal fluency and executive dysfunction in amyotrophic lateral sclerosis (ALS). Neuropsychologia, 38, 734-747.

AdolPhs, R., Damasio, H., \& Tranel, D. (2002). Neural systems for recognition of emotional prosody: A 3-D lesion study. Emotion, 2, 23-51.

Anderson, A. K., \& Phelps, E. A. (1998). Intact recognition of vocal expressions of fear following bilateral lesions of the human amygdala. NeuroReport, 9, 3607-3613.

Becker, F., \& Reinvang, I. (2007). Mismatch negativity elicited by tones and speech sounds: Changed topographical distribution in aphasia. Brain \& Language, 100, 69-78.

Bostanov, V., \& Kotchoubey, B. (2004). Recognition of affective prosody: Continuous wavelet measures of event-related brain potentials to emotional exclamations. Psychophysiology, 41, 259-268.

Brandeis, D., Lehmann, D., Michel, C. M., \& Mingrone, W. (1995). Mapping event-related brain potential microstates to sentence endings. Brain Topography, 8, 145-159.

Breitenstein, C., Daum, I., \& Ackermann, H. (1998). Emotional processing following cortical and subcortical brain damage: Contribution of the fronto-striatal circuitry. Behavioral Neurology, 11, 29-42.

Buchanan, T. W., Lutz, K., Mirzazade, S., Specht, K., Shah, N. J., ZILLES, K., \& JÄNCKE, L. (2000). Recognition of emotional prosody and verbal components of spoken language: An fMRI study. Cognitive Brain Research, 9, 227-238.

Connolly, J. F., \& D'ARCY, R. C. N. (2000). Innovations in neuropsychological assessment using event-related brain potentials. International Journal of Psychophysiology, 37, 31-47.

Connolly, J. F., Mate-Kole, C. C., \& Joyce, B. M. (1999). Global aphasia: An innovative assessment approach. Archives of Physical Medicine \& Rehabilitation, 80, 1309-1315.

Connolly, J. F., Phillips, N. A., Stewart, S. H., \& Brake, W. G. (1992). Event-related potential sensitivity to acoustic and semantic properties of terminal words in sentences. Brain \& Language, 43, 1-18.

Connolly, J. F., Service, E., D’Arcy, R. C. N., Kujala, A., \& Alho, K. 
(2001). Phonological aspects of word recognition as revealed by highresolution spatiotemporal brain mapping. NeuroReport, 12, 237-243.

Connolly, J. F., Stewart, S. H., \& Phillips, N. A. (1990). The effects of processing requirements on neurophysiological responses to spoken sentences. Brain \& Language, 39, 302-318.

Curran, T., Tucker, D. M., Kutas, M., \& Posner, M. I. (1993). Topography of the N400: Brain electrical activity reflecting semantic expectancy. Electroencephalography \& Clinical Neurophysiology, 88, 188-209.

Daltrozzo, J., Wioland, N., Mutschler, V., \& Kotchoubey, B. (2007). Predicting coma and other low responsive patients outcome using event-related brain potentials: A meta-analysis. Clinical Neurophysiology, 118, 606-614.

D'Arcy, R. C. N., Connolly, J. F., Service, E., Hawco, C. S., \& Houlihan, M. E. (2004). Separating phonological and semantic processing in auditory sentence processing: A high-resolution eventrelated brain potential study. Human Brain Mapping, 22, 40-51.

D'Arcy, R. C. N., Marchand, Y., Eskes, G. A., Harrison, E. R., PhilLIPS, S. J., MAJOR, A., \& ConNOLLY, J. F. (2003). Electrophysiological assessment of language function following stroke. Clinical Neurophysiology, 114, 662-672.

ECKSTEIN, K., \& Friederici, A. D. (2005). Late interaction of syntactic and prosodic processes in sentence comprehension as revealed by ERPs. Cognitive Brain Research, 25, 130-143.

Ethofer, T., Anders, S., Erb, M., Herbert, C., Wiethoff, S., Kissler, J., ET AL. (2006). Cerebral pathways in processing of affective prosody: A dynamic causal modeling study. NeuroImage, 30, 580-587.

Ethofer, T., Anders, S., Wiethoff, S., Erb, M., Herbert, C., SAUR, R., ET AL. (2006). Effects of prosodic emotional intensity on activation of associative auditory cortex. NeuroReport, 17, 249-253.

Friederici, A. D., Hahne, A., \& Mecklinger, A. (1996). Temporal structure of syntactic parsing: Early and late event-related brain potential effects. Journal of Experimental Psychology: Learning, Memory, \& Cognition, 22, 1219-1248.

Friederici, A. D., Pfeifer, E., \& Hahne, A. (1993). Event-related brain potentials during natural speech processing: Effects of semantic, morphological and syntactic violations. Cognitive Brain Research, 1, 183-192.

Giacino, J. T., Ashwal, S., Childs, N., Cranford, R., Jennett, B., KATZ, D. I., ET AL. (2002). The minimally conscious state: Definition and diagnostic criteria. Neurology, 58, 349-353.

Goffman, E. (1978). Response cries. Language, 54, 787-815.

Gratton, G., Coles, M. G. H., \& Donchin, E. (1983). A new method for off-line removal of ocular artifact. Electroencephalography \& Clinical Neurophysiology, 55, 468-484.

Grimshaw, G. M., Kwasny, K. M., Covell, E., \& Johnson, R. A. (2003). The dynamic nature of language lateralization: Effects of lexical and prosodic factors. Neuropsychologia, 41, 1008-1019.

HaAn, H., Streb, J., Bien, S., \& Rösler, F. (2000). Individual cortical current density reconstructions of the semantic N400 effect: Using a generalized minimum norm model with different constraints (L1 and L2 norm). Human Brain Mapping, 11, 178-192.

Halgren, E., Dhond, R. P., Christensen, N., Van Petten, C., MarinKovic, K., Lewine, J. D., \& Dale, A. M. (2002). N400-like magnetoencephalography responses modulated by semantic context, word frequency, and lexical class in sentences. NeuroImage, 17, 1106-1116.

Hanagasi, H. A., Gurvit, I. H., Ermutlu, N., Kaptanoglu, G., KaraMURSEL, S., Idrisoglu, H. A., ET AL. (2002). Cognitive impairment in amyotrophic lateral sclerosis: Evidence from neuropsychological investigation and event-related potentials. Cognitive Brain Research, 14, 234-244.

Hayashi, R., Imaizumi, S., Mori, K., NiImi, S., \& Ueno, S. (2001). Elicitation of $\mathrm{N} 400 \mathrm{~m}$ in sentence comprehension due to lexical prosody incongruity. NeuroReport, 12, 1753-1756.

Helenius, P., Salmelin, R., Service, E., Connolly, J. F., LeinoNEN, S., \& LyYTINEN, H. (2002). Cortical activation during spokenword segmentation in nonreading-impaired and dyslexic adults. Journal of Neuroscience, 22, 2936-2944.

Holcomb, P. J. (1993). Semantic priming and stimulus degradation: Implications for the role of the N400 in language processing. Psychophysiology, 30, 47-61.

Hornak, J., Bramham, J., Rolls, E. T., Morris, R. G., O’Doherty, J.,
Bullock, P. R., \& Polkey, C. E. (2003). Changes in emotion after circumscribed surgical lesions of the orbitofrontal and cingulate cortices. Brain, 126, 1691-1712.

HoRnAK, J., Rolls, E. T., \& WAdE, D. (1996). Face and voice expression identification in patients with emotional and behavioural changes following ventral frontal lobe damage. Neuropsychologia, 34, 241-261.

Humphries, C., Love, T., Swinney, D., \& Hickok, G. (2005). Response of anterior temporal cortex to syntactic and prosodic manipulations during sentence processing. Human Brain Mapping, 26, 128-138.

Imaizumi, S., Mori, K., Kiritani, S., Hosoi, H., \& Tonoike, M. (1998). Task-dependent laterality for cue decoding during spoken language processing. NeuroReport, 9, 899-903.

Isel, F., Alter, K., \& Friederici, A. D. (2005). Influence of prosodic information on the processing of split particles: ERP evidence from spoken German. Journal of Cognitive Neuroscience, 17, 154-167.

JennetT, B. (2002). The vegetative state: Medical facts, ethical and legal dilemmas. New York: Cambridge University Press.

Johnson, B. W., \& Hamm, J. P. (2000). High-density mapping in an N400 paradigm: Evidence for bilateral temporal lobe generators. Clinical Neurophysiology, 111, 532-545.

KAISER, J., \& LutZenberger, W. (2001). Location changes enhance hemispheric asymmetry of magnetic fields evoked by lateralized sounds in humans. Neuroscience Letters, 314, 17-20.

Kaiser, J., Lutzenberger, W., \& Birbaumer, N. (2000). Simultaneous bilateral mismatch response to right- but not leftward sound lateralization. NeuroReport, 11, 2889-2892.

Kaiser J., Lutzenberger, W., Preissl, H., Ackermann, H., \& BirBAUMER, N. (2000). Right-hemisphere dominance for the processing of sound-source lateralization. Journal of Neuroscience, 20, 6631-6639.

Kane, N. M., Curry, S. H., Butler, S. R., \& Cummins, B. H. (1993). Electrophysiological indicator of awakening from coma. Lancet, 341, 688.

Kane, N. M., Curry, S. H., Rowlands, C. A., Manara, A. R., Lewis, T., Moss, T., ET AL. (1996). Event-related potentials - neurophysiological tools for predicting emergence and early outcome from traumatic coma. Intensive Care Medicine, 22, 39-46.

Karniski, W., VANDERPloeg, R., \& Lease, L. (1993). "Virtual N400" and slow wave topography to auditory sentence incongruence. Brain \& Language, 44, 58-79.

Kawakubo, Y., Kamio, S., Nose, T., Iwanami, A., Nakagome, K., FUKUdA, M., ET AL. (2007). Phonetic mismatch negativity predicts social skills acquisition in schizophrenia. Psychiatry Research, 152, 261-265.

Kerkhofs, R., Vonk, W., Schriefers, H., \& Chwilla, D. J. (2007). Discourse, syntax, and prosody: The brain reveals an immediate interaction. Journal of Cognitive Neuroscience, 19, 1421-1434.

Korpilahti, P., Jansson-Verkasalo, E., Mattila, M.-L., KuUsikKo, S., Suominen, K., Rytky, S., ET AL. (2007). Processing of affective speech prosody is impaired in Asperger syndrome. Journal of Autism \& Developmental Disorders, 37, 1539-1549.

Kотсноubey, B. (in press). Vegetative state. In L. Squire (Ed.), Encyclopedia of neuroscience (4th ed.). Amsterdam: Elsevier.

Kotchoubey, B., \& Lang, S. (2003). Parallel processing of physical and lexical auditory information in humans. Neuroscience Research, 45, 369-374.

Kotchoubey, B., Lang, S., Bostanov, V., \& Birbaumer, N. (2003). Cortical processing in Guillain-Barré syndrome after years of total immobility. Journal of Neurology, 250, 1121-1123.

Kotchoubey, B., Lang, S., Mezger, G., Schmalohr, D., Schneck, M., Semmler, A., ET AL. (2005). Information processing in severe disorders of consciousness: Vegetative state and minimally conscious state. Clinical Neurophysiology, 116, 2441-2453.

Kotchoubey, B., Lang, S., Winter, S., \& Birbaumer, N. (2003). Cognitive processing in completely paralyzed patients with amyotrophic lateral sclerosis. European Journal of Neurology, 10, 551-558.

Kotz, S. A., Meyer, M., Alter, K., Besson, M., von Cramon, D. Y., \& FriederICI, A. D. (2003). On the lateralization of emotional prosody: An event-related functional MR investigation. Brain \& Language, 86, 366-376.

Kotz, S. A., \& Paulmann, S. (2007). When emotional prosody and semantics dance cheek to cheek: ERP evidence. Brain Research, 1151, 107-118. 
Kübler, A., Kotchoubey, B., Hinterberger, T., Ghanayim, N., Perelmouter, J., Schauer, M., ET AL. (1999). The thought translation device: A neurophysiological approach to communication in total motor paralysis. Experimental Brain Research, 124, 223-232.

Kujala, A., Alho, K., Service, E., Ilmoniemi, R. J., \& Connolly, J. F. (2004). Activation in the anterior left auditory cortex associated with phonological analysis of speech input: Localization of the phonological mismatch negativity response with MEG. Cognitive Brain Research, 21, 106-113.

Kutas, M., \& Hillyard, S. A. (1980). Reading senseless sentences: Brain potentials reflect semantic incongruity. Science, 207, 203-205.

LaKerveld, J., КотсHoubey, B., \& KüBLER, A. (2008). Cognitive function in patients with late stage amyotrophic lateral sclerosis. Journal of Neurology, Neurosurgery \& Psychiatry, 79, 25-29.

Laureys, S., Giacino, J. T., Schiff, N. D., Schabus, M., \& Owen, A. M. (2006). How should functional imaging of patients with disorders of consciousness contribute to their clinical rehabilitation needs? Current Opinion in Neurology, 19, 520-527.

LAVER, J. (1980). The phonetic description of voice quality. Cambridge: Cambridge University Press.

LIPSKI, S. C., \& MATHIAK, K. (2007). A magnetoencephalographic study on auditory processing of native and nonnative fricative contrasts in Polish and German listeners. Neuroscience Letters, 415, 90-95.

List, A., Justus, T., Robertson, L. C., \& Bentin, S. (2007). A mismatch negativity study of local-global auditory processing. Brain Research, 1153, 122-133.

Ludolph, A. C., Langen, K. J., Regard, M., Herzog, H., Kemper, B., KuwERT, T., ET AL. (1992). Frontal lobe function in amyotrophic lateral sclerosis: A neuropsychologic and positron emission tomography study. Acta Neurologica Scandinavica, 85, 81-89.

LÜTKENHÖNER, B., \& STEINSTRÄTER, O. (1998). High-precision neuromagnetic study of the functional organization of the human auditory cortex. Audiology \& Neuro-Otology, 3, 191-213.

Magne, C., Astésano, C., Lacheret-Dujour, A., Morel, M., Alter, K., \& Besson, M. (2005). On-line processing of "pop-out" words in spoken French dialogues. Journal of Cognitive Neuroscience, 17, 740-756.

Mäkelë, A. M., Mäkinen, V., Nikkilä, M., Ilmoniemi, R. J., \& Tirtinen, H. (2001). Magnetoencephalographic (MEG) localization of the auditory N400m: Effects of stimulus duration. NeuroReport, 12, 249-253.

Marslen-Wilson, W. D., Tyler, L. K., Warren, P., Grenier, P., \& LEE, C. S. (1992). Prosodic effects in minimal attachment. Quarterly Journal of Experimental Psychology, 45A, 73-87.

Mathiak, K., Hertrich, I., Lutzenberger, W., \& Ackermann, H. (1999). Preattentive processing of consonant vowel syllables at the level of the supratemporal plane: A whole-head magnetencephalography study. Cognitive Brain Research, 8, 251-257.

Mathiak, K., Rapp, A., Kircher, T. T. J., Grodd, W., Hertrich, I., WeISKOPF, N., ET AL. (2002). Mismatch responses to randomized gradient switching noise as reflected by fMRI and whole-head magnetoencephalography. Human Brain Mapping, 16, 190-195.

McCarthy, G., \& Wood, C. C. (1985). Scalp distributions of event-related potentials: An ambiguity associated with analysis of variance models. Electroencephalography \& Clinical Neurophysiology, 62, 203-208.

Mecklinger, A., Schriefers, H., Steinhauer, K., \& Friederici, A. D. (1995). Processing relative clauses varying on syntactic and semantic dimensions: An analysis with event-related potentials. Memory \& Cognition, 23, 477-494.

Mietz, A., Toepel, U., Ischebeck, A., \& Alter, K. (2008). Inadequate and infrequent are not alike: ERPs to deviant prosodic patterns in spoken sentence comprehension. Brain \& Language, 104, 159-169.

Mitchell, R. L. C., Elliott, R., Barry, M., Cruttenden, A., \& Woodruff, P. W. R. (2003). The neural response to emotional prosody, as revealed by functional magnetic resonance imaging. Neuropsychologia, 41, 1410-1421.

Mueller, V., Brehmer, Y., von Oertzen, T., Li, S.-C., \& LindenBERGER, U. (2008). Electrophysiological correlates of selective attention: A lifespan comparison. BMC Neuroscience, 9, 1-21.

Münte, T. F., Heinze, H.-J., Matzke, M., Wieringa, B. M., \& JoHANNES, S. (1998). Brain potentials and syntactic violations revisited: No evidence for specificity of the syntactic positive shift. Neuropsychologia, 36, 217-226.
Münte, T. F., Wieringa, B. M., Weyerts, H., Szentkuti, A., Matzke, M., \& Johannes, S. (2001). Differences in brain potentials to open and closed class words: Class and frequency effects. Neuropsychologia, 39, 91-102.

NäÄtÄnen, R. (1992). Attention and brain function. Hillsdale, NJ: Erlbaum.

NÄÄTÄNEN, R., \& WINKLER, I. (1999). The concept of auditory stimulus representation in cognitive neuroscience. Psychological Bulletin, 125, 826-859.

Nakagome, K., Takazawa, S., Kanno, O., Hagiwara, H., NaKaJima, H., IтоH, K., \& KoshidA, I. (2001). A topographical study of ERP correlates of semantic and syntactic violations in the Japanese language using the multichannel EEG system. Psychophysiology, 38, 304-315.

Neumann, N., \& Kotchoubey, B. (2004). Assessment of cognitive functions in severely paralysed and severely brain-damaged patients: Neuropsychological and electrophysiological methods. Brain Research Protocols, 14, 25-36.

Newman, R. L., \& Connolly, J. F. (2004). Determining the role of phonology in silent reading using event-related brain potentials. Cognitive Brain Research, 21, 94-105.

Nobre, A. C., \& McCarthy, G. (1994). Language-related ERPs: Scalp distributions and modulation by word type and semantic priming. Journal of Cognitive Neuroscience, 6, 233-255.

Osterhout, L., Holcomb, P. J., \& Swinney, D. A. (1994). Brain potentials elicited by garden-path sentences: Evidence of the application of verb information during parsing. Journal of Experimental Psychology: Learning, Memory, \& Cognition, 20, 786-803.

Owen, A. M., Coleman, M. R., Boly, M., Davis, M. H., Laureys, S., \& PICKARD, J. D. (2006). Detecting awareness in the vegetative state. Science, 313, 1402.

Pannekamp, A., Toepel, U., Alter, K., Hahne, A., \& Friederici, A. D. (2005). Prosody-driven sentence processing: An event-related brain potential study. Journal of Cognitive Neuroscience, 17, 407-421.

Pantev, C., Bertrand, O., Eulitz, C., Verkindt, C., Hampson, S., Schuierer, G., \& Elbert, T. (1995). Specific tonotopic organizations of different areas of the human auditory cortex revealed by simultaneous magnetic and electric recordings. Electroencephalography \& Clinical Neurophysiology, 94, 26-40.

Paulmann, S., \& Kotz, S. A. (2008a). Early emotional prosody perception based on different speaker voices. NeuroReport, 19, 209-213.

Paulmann, S., \& Kotz. S. A. (2008b). An ERP investigation on the temporal dynamics of emotional prosody and emotional semantics in pseudo- and lexical-sentence context. Brain \& Language, 105, 59-69.

Paulus, K. S., Magnano, I., Piras, M. R., Solinas, M. A., SoliNAS, G., SAU, G. F., \& Aiello, I. (2002). Visual and auditory eventrelated potentials in sporadic amyotrophic lateral sclerosis. Clinical Neurophysiology, 113, 853-861.

Perry, R. J., Rosen, H. R., Kramer, J. H., Beer, J. S., Levenson, R. L., \& Miller, B. L. (2001). Hemispheric dominance for emotions, empathy and social behaviour: Evidence from right and left handers with frontotemporal dementia. Neurocase, 7, 145-160.

Plante, E., Holland, S. K., \& Schmithorst, V. J. (2006). Prosodic processing by children: An fMRI study. Brain \& Language, 97, 332342.

Pulvermüller, F., Shtyrov, Y., Hasting, A. S., \& Carlyon, R. P. (2008). Syntax as a reflex: Neurophysiological evidence for early automaticity of grammatical processing. Brain \& Language, 104, 244-253.

ReINVANG, I. (1999). Cognitive event-related potentials in neuropsychological assessment. Neuropsychology Review, 9, 231-248.

RÖSLER, F., STREB, J., \& HAAN, H. (2001). Event-related brain potentials evoked by verbs and nouns in a primed lexical decision task. Psychophysiology, 38, 694-703.

Ross, E. D. (1981). The aprosodias: Functional-anatomic organization of the affective components of language in the right hemisphere. Archives of Neurology, 38, 561-569.

Ross, E. D., Orbelo, D. M., Burgard, M., \& Hansel, S. (1998). Functional-anatomic correlates of aprosodic deficits in patients with right brain damage. Neurology, 50, A363.

Rossell, S. L., Price, C. J., \& Nobre, A. C. (2003). The anatomy and time course of semantic priming investigated by fMRI and ERPs. Neuropsychologia, 41, 550-564.

Röttger, S., Schröger, E., Grube, M., Grimm, S., \& RübSamen, R. 
(2007). Mismatch negativity on the cone of confusion. Neuroscience Letters, 414, 178-182.

Royal Colleges of Physicians (2003). The permanent vegetative state: A working party report. London: Royal Colleges of Physicians.

Ruusuvirta, T., Huotilainen, M., \& NäÄtänen, R. (2007). Preperceptual human number sense for sequential sounds, as revealed by mismatch negativity brain response? Cerebral Cortex, 17, 2777-2779.

Sambeth, A., Ruohio, K., Alku, P., Fellman, V., \& Huotilainen, M. (2008). Sleeping newborns extract prosody from continuous speech. Clinical Neurophysiology, 119, 332-341.

Sander, D., Grandjean, D., Pourtois, G., Schwartz, S., Seghier, M. L., Scherer, K. R., \& Vuilleumier, P. (2005). Emotion and attention interactions in social cognition: Brain regions involved in processing anger prosody. Neurolmage, 28, 848-858.

SCHEFFÉ, H. (1959). The analysis of variance. New York: Wiley.

SCHERER, K. R. (1986). Vocal affect expression: A review and a model for future research. Psychological Bulletin, 99, 143-165.

Scherer, K. R., \& KaPPAS, A. (1988). Primate vocal expression of affective states. In D. Todt, P. Goedeking, E. Newman, \& D. Symmes (Eds.), Primate vocal communication (pp. 171-194). Berlin: Springer.

Schirmer, A., \& Kotz, S. A. (2006). Beyond the right hemisphere: Brain mechanisms mediating vocal emotional processing. Trends in Cognitive Sciences, 10, 24-30.

Schirmer, A., Kotz, S. A., \& Friederici, A. D. (2002). Sex differentiates the role of emotional prosody during word processing. Cognitive Brain Research, 14, 228-233.

Schirmer, A., Kotz, S. A., \& Friederici, A. D. (2005). On the role of attention for the processing of emotions in speech: Sex differences revisited. Cognitive Brain Research, 24, 442-452.

SCHRÖGER, E. (1997). On the detection of auditory deviations: A preattentive activation model. Psychophysiology, 34, 245-257.

SCHRÖGER, E., \& WolfF, C. (1997). Fast preattentive processing of location: A functional basis for selective listening in humans. Neuroscience Letters, 232, 5-8.

SEDDOH, S. A. (2002). How discrete or independent are "affective prosody" and "linguistic prosody"? Aphasiology, 16, 683-692.

Shtyrov, Y., Kujala, T., Ahveninen, J., Tervaniemi, M., Alku, P., ILMONIEMI, R. J., \& NÄÄTÄNEN, R. (1998). Background acoustic noise and the hemispheric lateralization of speech processing in the human brain: Magnetic mismatch negativity study. Neuroscience Letters, 251, 141-144.

Silva-Pereyra, J., Harmony, T., Villanueva, G., Fernández, T., Rodriguez, M., Galán, L., ET AL. (1999). N400 and lexical decisions: Automatic or controlled processing? Clinical Neurophysiology, 110, 813-824.

SRINIVASAN, N., \& BAIJAL, S. (2007). Concentrative meditation enhances preattentive processing: A mismatch negativity study. NeuroReport, 18, 1709-1712.

STEINHAUER, K. (2003). Electrophysiological correlates of prosody and punctuation. Brain \& Language, 86, 142-164.

Steinhauer, K., Alter, K., \& Friederici, A. D. (1999). Brain potentials indicate immediate use of prosodic cues in natural speech processing. Nature Neuroscience, 2, 191-196.
Steinhauer, K., \& Friederici, A. D. (2001). Prosodic boundaries, comma rules, and brain responses: The closure positive shift in ERPs as a universal marker for prosodic phrasing in listeners and readers. Journal of Psycholinguistic Research, 30, 267-295.

Strong, M. J., Grace, G. M., Orange, J. B., \& Leeper, H. A. (1996). Cognition, language, and speech in amyotrophic lateral sclerosis: A review. Journal of Clinical \& Experimental Neuropsychology, 18, 291-303.

Thönnessen, H., Zvyagintsev, M., Harke, K. C., Boers, F., DamMERS, J., Norra, C., \& MathiaK, K. (2008). Optimized mismatch negativity paradigm reflects deficits in schizophrenia patients: A combined EEG and MEG study. Biological Psychology, 77, 205-216.

Tittinen, H., May, P., Reinikainen, K., \& NäÄtänen, R. (1994). Attentive novelty detection in humans is governed by pre-attentive sensory memory. Nature, $\mathbf{3 7 2}, 90-92$.

Van Petten, C., \& Luka, B. J. (2006). Neural localization of semantic context effects in electromagnetic and hemodynamic studies. Brain \& Language, 97, 279-293.

VERLEGER, R. (1988). Event-related potentials and cognition: A critique of the context updating hypothesis and an alternative interpretation of P3. Behavioral \& Brain Sciences, 11, 343-356.

Vieregge, P., Wauschiuhn, B., Heberlein, I., Hagenah, J., \& VerLEGER, R. (1999). Selective attention is impaired in amyotrophic lateral sclerosis: A study of event-related EEG potentials. Cognitive Brain Research, 8, 27-35.

WambacQ, I. J. A., Shea-Miller, K. J., \& Abubakr, A. (2004). Nonvoluntary and voluntary processing of emotional prosody: An eventrelated potentials study. NeuroReport, 15, 555-559.

Wiethoff, S., Wildgruber, D., Kreifelts, B., Becker, H., HerBert, C., GrodD, W., \& Ethofer, T. (2008). Cerebral processing of emotional prosody -influence of acoustic parameters and arousal. NeuroImage, 39, 885-893.

Wildgruber, D., Riecker, A., Hertrich, I., Erb, M., Grodd, W., Ethofer, T., \& ACKermann, H. (2005). Identification of emotional intonation evaluated by fMRI. NeuroImage, 24, 1233-1241.

Wijnen, V. J. M., van Boxtel, G. J. M., Eilander, H. J., De Gelder, B. (2007). Mismatch negativity predicts recovery from the vegetative state. Clinical Neurophysiology, 118, 597-605.

\section{NOTES}

1. Some MCS patients had been examined before the exact criteria of MCS were published (Giacino et al., 2002) and were that time regarded as "probable PVS" or "inconsistently unconscious."

2. Duration is largely irrelevant in many EEG and MEG experiments in which the critical responses are recorded long before the offset of the stimuli.

3. The authors obtained the largest activation in the middle right temporal gyrus, in contrast to the superior right temporal gyrus found most active in many other studies. This incongruence cannot be discussed here.

(Manuscript received September 8, 2008; revision accepted for publication November 26, 2008.) 